\title{
Simulation of community metabolism and atmospheric carbon dioxide and oxygen concentrations in Biosphere 2
}

\author{
Victor C. Engel ${ }^{\mathrm{a}, *}$, H.T. Odum ${ }^{\mathrm{b}}$ \\ ${ }^{a}$ Lamont-Doherty Earth Observatory of Columbia University, Palisades, New York 10964, USA \\ ${ }^{\mathrm{b}}$ Department of Environmental Engineering Sciences, University of Florida, Gainesville, \\ FL 32611-2013, USA
}

Received 7 October 1996; received in revised form 20 October 1997; accepted 28 October 1997

\begin{abstract}
The complexity and scale of Biosphere 2 under materially closed conditions represented a unique opportunity to investigate couplings between elemental cycles and community metabolism. For this paper, simulation models were developed to explore individual biome effects on atmospheric composition and carbon cycling inside the enclosure. Results suggest soil respiration rates, light intensity, and acid-base equilibrium control atmospheric carbon dioxide and oxygen under materially closed conditions. Experiments with the overall Combined Biome model indicate: (1) the agriculture biome has a greater effect on atmospheric composition than the other biomes due to its large area, high net productivity, and biomass harvests; (2) the rainforest, which occupies $\approx 20 \%$ of Biosphere 2 area, may be responsible for $50 \%$ of total community production and respiration of oxygen; (3) the savannah and wetland biomes may be sources of carbon dioxide in the long term; (4) the ocean biome has less effect on atmospheric composition than the terrestrial biomes; and (5) the desert biome may lower carbon dioxide in the atmosphere as much as $2000 \mathrm{ppm}$ during low light. Diurnal curve analyses of oxygen and carbon dioxide from early 1995 produced an average community gross production rate of $23 \mathrm{~g} \mathrm{O}_{2} / \mathrm{m}^{2}$ per day, a community respiration rate of $25 \mathrm{~g} \mathrm{O}_{2} / \mathrm{m}^{2}$ per day, and an average carbon dioxide absorption rate of $0.2 \mathrm{~g} \mathrm{CO}_{2} / \mathrm{m}^{2}$ per h. (C) 1999 Published by Elsevier Science B.V. All rights reserved.
\end{abstract}

Keywords: Biosphere 2; Community metabolism; Agriculture biome; Rainforest biome; Ocean biome; Atmosphere; Carbon dioxide; Oxygen; Modeling

\footnotetext{
* Corresponding author. Tel.: + 1-212-7499541.

E-mail address: vengel@ldeo.columbia.edu (V.C. Engel)
}

0925-8574/99/\$ - see front matter (C) 1999 Published by Elsevier Science B.V. All rights reserved.

PII: S0925-8574(98)00094-9 


\section{Introduction}

Understanding the processes by which the self organization of life and biogeochemical cycles interact is a main objective in systems ecology. The composition of Earth's atmosphere is understood to respond to the combined effects of global metabolism and geochemical recycling, just as these processes are influenced in turn by the atmosphere. Can the changes in atmospheric carbon dioxide and oxygen be accounted for using models of the main processes mentioned above? While global experimentation is not possible, and too simple models are not likely to be credible for the whole earth, the mesoscale complexity of Biosphere 2 provides an opportunity to test our knowledge of biogeochemical processes and how they interact.

One operational theory behind the Biosphere 2 enclosure was the idea of a balanced ecosystem in which photosynthesis fixed carbon dioxide and generated oxygen while respiration of plants, microbes, and animals used oxygen and regenerated carbon dioxide at equivalent rates. Several authors investigated these cycles of carbon and oxygen in Biosphere 2 during the first years of operation. As part of a chapter on closed microcosms, Beyers and Odum (1994) published a model of Biosphere 2 using estimates of flows and storages identifying the effect of carbonates on carbon dioxide concentrations. Their work also explored the effect of different quantities of organic matter at the start in generating excess carbon dioxide or oxygen. In another study, Severinghaus (1994) presented estimates of carbon dioxide flows including uptake by the concrete using carbon isotopes. A static model with a budget for average flows and storages of carbon was prepared by Dempster (1993) using observational data. Engel (1994) simulated the individual biomes in Biosphere 2 to estimate long term concentrations of atmospheric gases. This paper presents these results with some further modifications. Computer simulation models were revised to help understand and predict biogeochemical processes inside the enclosure. Insights into the organization of the biotic and abiotic elements were sought for understanding the Earth as a whole.

\section{Plan of research}

Two approaches were taken to simulate biogeochemical cycles inside Biosphere 2. For the first approach individual biome models were developed and simulated independently. These individual biome models were then linked to form a more comprehensive program (Fig. 1, here after referred to as the Combined Biome model) designed to represent the overall system. Individual biome models were used to test the effects of altering starting conditions such as the ratio of gross to net production, soil organic matter concentrations, and the rate of carbon dioxide absorption by calcareous materials. The Combined Biome model was used to examine the influence of each individual biome on the overall system.

A more simplified approach to the simulation of conditions inside Biosphere 2 was developed using a minimum of storage variables and material transfers. Community metabolism in this model (Fig. 2, hereafter referred to as the Mini 
model) was calibrated from observed, diurnal curves of oxygen and carbon dioxide from January and February, 1995. Values for internal storages and transfer processes, where applicable, were derived from averages taken over all the individual biomes. The responses of community metabolic rates and atmospheric gases to changes in starting conditions were also explored using this simplified model.

Because of the complexity of Biosphere 2, not all interior processes could be represented in these models. Factors not considered limiting to production, such as nutrient availability, were excluded. Accurately calibrating these models to initial conditions required detailed knowledge of internal storage variables of soil organic matter, biomass accumulations, atmospheric gas concentrations, as well as the reaction rates of transfer processes that link these reservoirs. This information, however, was often not available during the initial 2 year closure period when many of the individual biome models were developed. To compensate, process rate data from analog biomes outside Biosphere 2 were used to estimate transfer coefficients. Long term simulations assumed a materially closed system, and most do not

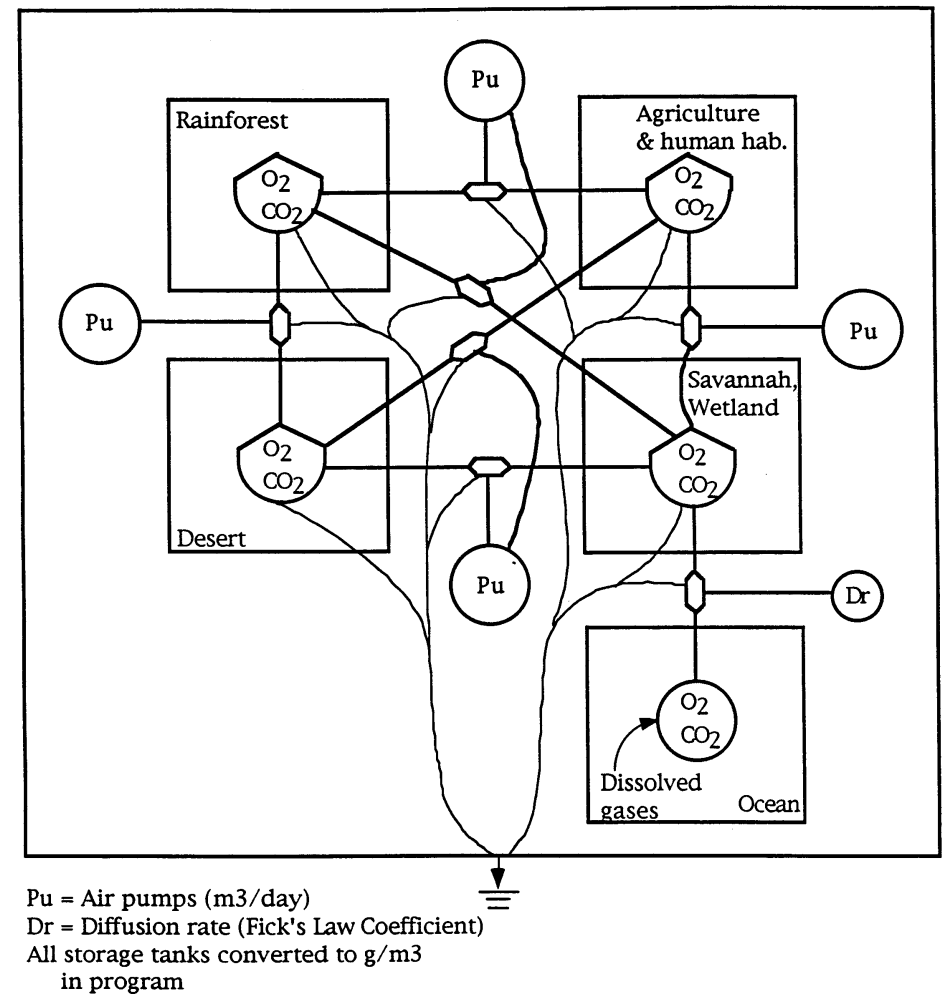

Fig. 1. The Combined Biome model of Biosphere 2 representing atmospheric exchanges between biomes. Individual biomes are symbolized for simplicity in this diagram. The simulation model contains all the principle components of each biome, including oxygen, plant biomass, soil organic matter, and calcareous substances. 


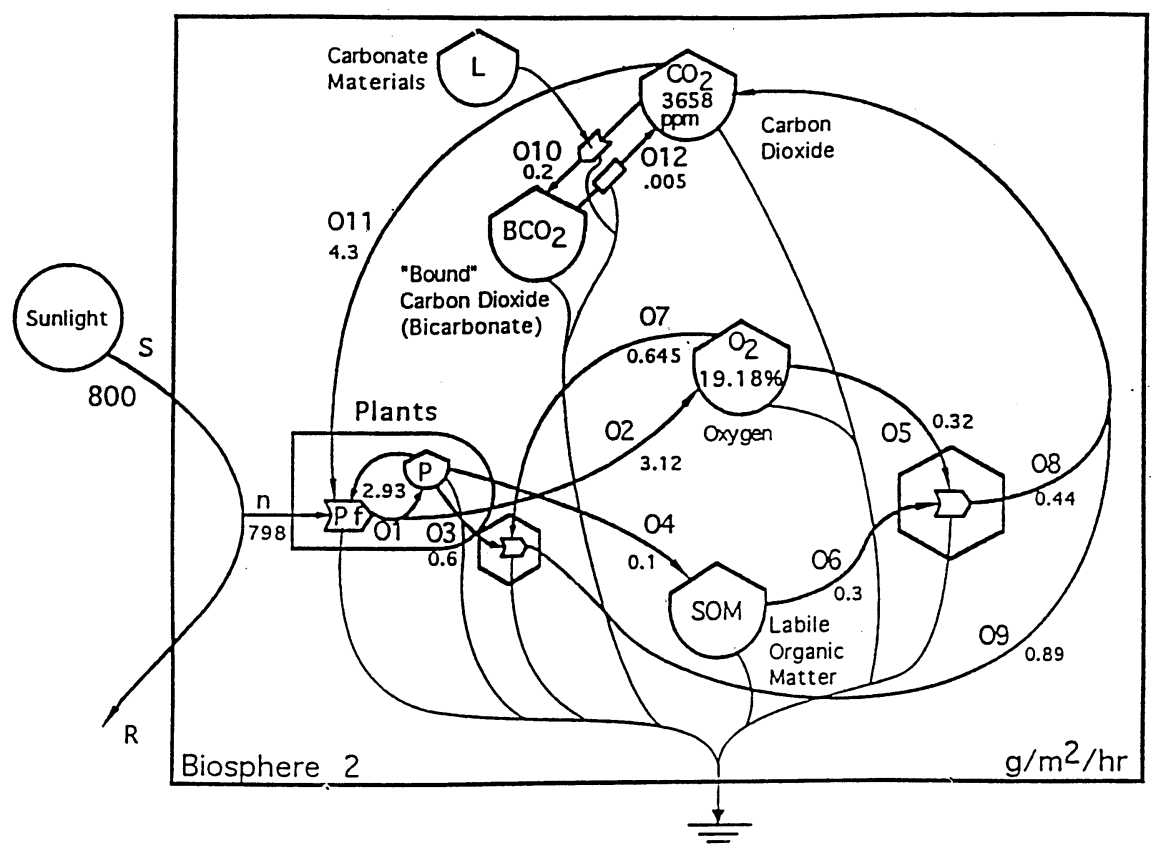

Equations:

$$
\begin{aligned}
& R=S /(1+n * P \star C O 2) \\
& \mathrm{Pf}=\mathrm{R} \mathrm{Pf}^{\star} \mathrm{CO} 2 \\
& \triangle P=01 * P f-03 * P \star 02-04 * P \\
& \triangle \mathrm{CO} 2=08 \mathrm{SOM}^{\star} \mathrm{O} 2+09{ }^{*} \mathrm{O} 2{ }^{\star} \mathrm{P} \\
& +012 \star \mathrm{BCO} 2-011^{\star \mathrm{Pf}}
\end{aligned}
$$

$$
\begin{array}{r}
\Delta O 2=022^{\star} \mathrm{Pf}-05^{\star} \mathrm{O}{ }^{\star} \mathrm{SOM}-07^{\star} \mathrm{O} 2^{\star} \mathrm{P} \\
\triangle \mathrm{SOM}=04^{\star} \mathrm{P}-06^{\star} \mathrm{SOM} \mathrm{M}^{\star} \mathrm{O} 2 \\
\triangle \mathrm{BCO2}=010^{\star} \mathrm{CO2} \mathrm{L}-012^{\star} \mathrm{BCOZ} \\
\Delta \mathrm{t}=1 \text { hour }
\end{array}
$$

Fig. 2. Energy system diagram and equations of the Mini model of metabolism inside Biosphere 2.

account for human intervention. Imprecise values for internal storages and management impacts affected primarily the long term simulations of these models, where predicted and observed conditions were most divergent. However, short term simulations were less affected, and where possible, management practices were included.

\section{Methods}

\subsection{Modelling and simulation procedures}

The procedures for generating the individual biome and Combined Biome simulation models for Biosphere 2 followed the same guidelines described below. 


\title{
3.1.1. Identify system components and draw an energy diagram
}

The principle factors believed to be involved in the regulation of community metabolism in a biome were identified. Each model contains functions for light, photosynthesis, community respiration, and a simplified carbonate system. Storages and material flows were diagrammed according to the energy systems language proposed by Odum $(1967,1971,1983)$. This energy language concurrently shows the energetics, storages, material flows, the position in the energy hierarchy, and suggests the mathematical relationships for each of the variables in a system. Fig. 3 identifies and explains each of the symbols used in this energy language.

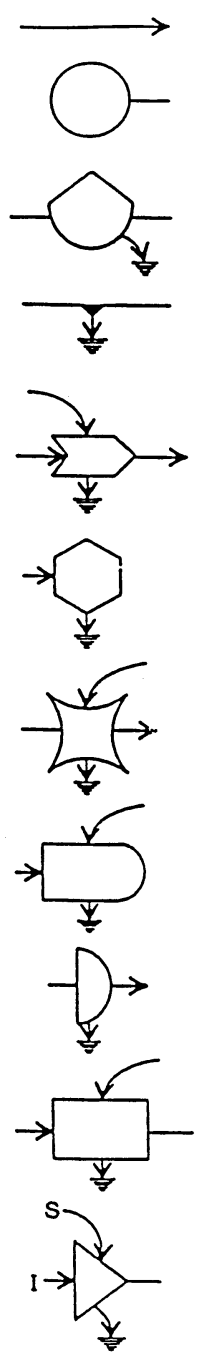

\begin{abstract}
Energy circuit. A pathway whose flow is proportional to the quantity in the storage or source upstream.

Source. Outside source of energy delivering forces according to a program controlled from outside; a forcing function.

Tank. A compartment of energy storage within the system storing a quantity as the balance of inflows and outflows; a state variable.
\end{abstract}

Heat sink. Dispersion of potential energy into heat that accomparies all real transformation processes and storages; loss of potential energy from further use by the system.

Interaction. Interactive intersection of two pathways coupled to produce an outflow in proportion to a function of both; control action of one flow on another; limiting factor action; work gate.

Consumer. Unit that transforms energy quality, stores it, and feeds it back autocatalytically to improve inflow.

Switching action. A symbol that indicates one or more switching actions.

Producer. Unit that collects and transforms low-quality energy under control interactions of high-quality flows.

Self-limiting energy receiver. A unit that has a self-limiting output when input drives are high because there is a limiting constant quality of material reacting on a circular pathway within.

Box. Miscellaneous symbol to use for whatever unit or function is labeled.

Constant-gain amplifier. A unit that delivers an output in proportion to the input I but changed by a constant factor as long as the energy source $S$ is sufficient.

Fig. 3. Symbols of energy language used to represent systems (Odum, 1983) 


\subsubsection{Determine the corresponding differential equations}

The differential equations used for simulation were derived from the systems diagram and used to develop the computer program. An example of a set of differential equations determined from a systems diagram is given in Fig. 2. Transfer coefficients in Fig. 2 are identified with the prefix ' $O$ ' followed by a number. State variables are identified by a string of capital letters. See Section 3.1.4 below for a description of the method used to determine constant values for the transfer coefficients. Numerical solutions to the differential equations derived from the system diagrams were graphed as a function of time for simulation results using QuickBasic. The simulation times for the individual and Combined biome models correspond to 3 years with iterations between 12 and $24 \mathrm{~h}$. Ocean biome simulations cover 15 days, with hourly iterations. The Mini model of Biosphere 2 was calibrated to simulate two to three week intervals with iterations every $15 \mathrm{~min}$.

\subsubsection{Assemble the data for calibration}

Once a diagram and corresponding differential equations had been produced for a biome model, transfer processes (represented by arrows in the systems diagrams) and storages (represented using the tank symbols) were assigned a numeric value. Material transfer rate units were expressed as g per square meter per year $\left(\mathrm{g} / \mathrm{m}^{2}\right.$ per year), while grams per square meter $\left(\mathrm{g} / \mathrm{m}^{2}\right)$ were chosen for storages. Observed values of atmospheric carbon dioxide and oxygen and sunlight were used to calibrate the individual biome models to initial conditions.

Changes in plant biomass inside Biosphere 2 over a 2.5 year period (Bierner, 1994) were used to estimate production and litterfall rates in the individual biome and Combined Biome models. The reader is referred to Engel (1994) for a description on how changes in above ground biomass were converted to daily production values. Data on biomass changes in the Agriculture biomes were unavailable and were estimated from literature values based on the species list of crops grown inside. Ocean productivity was estimated from literature values (Adey, 1991) Direct, observational data on photosynthetic efficiency, soil respiration rates, respiration quotients, and soil organic matter concentrations were not available during calibration of the individual biome models, so representative values from analogue systems were used as estimates or normalized to unity for calibration.

\subsubsection{Determine transfer coefficients}

Steady state numerical values assigned to material and energy transfers were used to calculate transfer coefficients from the expressions corresponding to that process. The reader is referred to the set of differential equations in Fig. 2 as an example. The terms describing material or energy transfers on the right hand side of the differential equations in Fig. 2 were equated with the numerical value chosen for that process. A spreadsheet (Table 2) was used to calculate the transfer coefficients by dividing the chosen numerical value of the transfer process (Table 2, column 2) by the initial values of the storages (represented using capital letters) included in the expressions. After the coefficients were calculated (Table 2, column 3), they were imported as constants into the QuickBasic program for computer simulation. 
Table 1

Summary results of community metabolism and carbon dioxide absorption rates derived from diurnal changes in atmospheric carbon dioxide and oxygen inside Biosphere 2 between January and February $1995^{\mathrm{a}}$

\begin{tabular}{llllll}
\hline Dates & $\begin{array}{l}\mathrm{GPP}^{\mathrm{b}} \\
\mathrm{g} \mathrm{O}_{2} \mathrm{~m}^{-2} \mathrm{~h}^{-1}\end{array}$ & $\begin{array}{l}\mathrm{GPP}^{\mathrm{b}} \\
\mathrm{g} \mathrm{CO}_{2} \mathrm{~m}^{-2} \mathrm{~h}^{-1}\end{array}$ & $\begin{array}{l}\mathrm{Ra}_{\mathrm{g} \mathrm{O}} \\
\mathrm{g} \mathrm{m}^{-2} \mathrm{~h}^{-1}\end{array}$ & $\begin{array}{l}\mathrm{Ra}_{\mathrm{co}} \\
\mathrm{g} \mathrm{CO}_{2} \mathrm{~m}^{-2} \mathrm{~h}^{-1}\end{array}$ & $\begin{array}{l}\text { Absorption } \\
\mathrm{g} \mathrm{CO}_{2} \mathrm{~m}^{-2} \mathrm{~h}^{-1}\end{array}$ \\
\hline $\begin{array}{l}1 / 1 / 95-1 / 31 / 95 \\
2 / 1 / 95-2 / 28 / 95\end{array}$ & $5.04(8.9)$ & $6.94(12.2)$ & $1.3(1.6)$ & $1.8(2.2)$ & $0.51(1.9)$ \\
$\begin{array}{l}\text { Overall } \\
\text { averages }\end{array}$ & 3.2 & $1.5(4.5)$ & $0.6(0.9)$ & $0.8(1.3)$ & $-0.2(0.9)$ \\
& 4.3 & 0.9 & 1.3 & 0.2 \\
\hline
\end{tabular}

a All values are averages. S.D. are included in parentheses. Data sets were combined to generate values used to calibrate the mini model in Fig. 3.

${ }^{\mathrm{b}} \mathrm{GPP}$, gross primary production.

${ }^{\mathrm{c}} \mathrm{Ra}$, community respiration.

\subsubsection{Graph and print simulation results}

Starting with the program as initially calibrated, changes in the individual and Combined biome model variables over time were displayed on a computer monitor. Scaling factors were utilized in the QuickBasic programs to standardize vertical axes and to organize simulation displays. Screen images were converted to a format for the drawing program Canvas ${ }^{\mathrm{TM}}$ to add legends. For later Mini model simulations, results were written to an Excel ${ }^{\mathrm{TM}}$ spreadsheet and graphed. Each program was modified and simulated under variable starting conditions and transfer process rates. The responses of community metabolic rates and atmospheric composition to changes in starting conditions were revealed through these experimental tests.

\subsection{Calculating community metabolism from diurnal changes in atmospheric composition}

Changes in atmospheric gases in Biosphere 2 were recorded every 15 min during January and February, 1995. Pressure changes of carbon dioxide and oxygen were combined with the Ideal Gas Law, the estimated, approximate volume $\left(134317 \mathrm{~m}^{3}\right)$ and area $\left(9124 \mathrm{~m}^{2}\right)$ of Biosphere 2 in Eq. (1) and Eq. (2) below to determine rates of gross photosynthesis, community respiration, and absorption of carbon dioxide. These values were used to calibrate the Mini model of metabolism (Section 3.4). An example will be used to demonstrate how community metabolism and carbon dioxide absorption rates were determined from changes in atmospheric gases.

In a given $24 \mathrm{~h}$ period, the concentration of carbon dioxide in Biosphere 2 might begin at an early morning high of $2650 \mathrm{ppm}$, decrease $775-1875 \mathrm{ppm}$ during $10 \mathrm{~h}$ of sunlight, and then increase again to $2650 \mathrm{ppm}$ during $14 \mathrm{~h}$ below the photosynthetic compensation point. Decreases in atmospheric carbon dioxide were expressed using the Ideal Gas Law:

$$
\mathrm{dCO}_{2}=\frac{(-7.75 \mathrm{E}-4 \mathrm{~atm}) *\left(134317 \mathrm{~m}^{3}\right)}{\left(8.12 \mathrm{E}-5 \mathrm{~m}^{3} \mathrm{~atm}(\mathrm{~mol} \mathrm{~K})\right) *(298 \mathrm{~K})}=-4254 \mathrm{~mol}
$$


therefore,

$$
\begin{aligned}
= & \frac{(-4254 \mathrm{~mol}) *(44 \mathrm{~g} / \mathrm{mol})}{\left(9124 \mathrm{~m}^{2}\right) *(10 \mathrm{~h})}=-2.05 \mathrm{~g} \mathrm{CO}_{2} \mathrm{~m}^{-2} \mathrm{~h}^{-1} \\
& \text { (net photosynthesis }+ \text { absorption) }
\end{aligned}
$$

$\mathrm{R}$, gas constant; $\mathrm{dn}, \mathrm{dPV} / \mathrm{RT}$; $\mathrm{n}$, moles; $\mathrm{P}$, pressure; $\mathrm{V}$, volume; $\mathrm{T}$, Kelvin temperature; volume of Bio 2, $134317 \mathrm{~m}^{3}$; area of Bio 2, $9124 \mathrm{~m}^{2}$.

Using Eq. (1), the net hourly rate of change in the concentrations of carbon dioxide were determined on a $\mathrm{g} \mathrm{CO}_{2} / \mathrm{m}^{2}$ per $\mathrm{h}$ basis. Decreases in carbon dioxide were assumed to represent net photosynthesis plus absorption and were substituted into Eq. (2) as $\mathrm{dCO}_{2} / \mathrm{dt}$.

$$
\frac{\mathrm{dCO}_{2}}{\mathrm{dt}}=\mathrm{GPP}-\mathrm{Ra} \pm \mathrm{A}
$$

where, $\mathrm{dCO}_{2}$, change in the concentration of carbon dioxide $\left(\mathrm{g} \mathrm{CO}_{2} \mathrm{~m}^{-2} \mathrm{~h}^{-1}\right)$; GPP, gross rate of primary production; Ra, rate of community respiration; A, rate of absorption/release of carbon dioxide by carbonate containing materials; $\mathrm{dt}$, time interval.

Because of the unknown value of absorption (A), however, Eq. (2) cannot be solved for gross production and respiration using changes in carbon dioxide alone. To compensate, changes in atmospheric oxygen concentrations were used to determine rates of gross production and community respiration. Eq. (1) was also used to determine these rates, (in the example, substituting oxygen for carbon dioxide).

If applied to changes in oxygen concentrations, Eq. (1) yields values for net production (using increases in partial pressure of oxygen) and respiration (using subsequent decreases in partial pressure of oxygen) in terms of $\mathrm{g} \mathrm{O}_{2} \mathrm{~m}^{-2} \mathrm{~h}^{-1}$. For these calculations, it was assumed that there exists no abiotic sink of oxygen within Biosphere 2 to affect the diurnal changes in the atmosphere. The hourly rate for net production of oxygen was added to the hourly rate for community respiration to determine gross production (GPP). Gross production and respiration rates (in terms of $\mathrm{g} \mathrm{O}_{2} / \mathrm{m}_{2}$ per $\mathrm{h}$ ) were then converted to an equivalent mass of carbon dioxide by multipling by the molecular weight ratio (44/32) to yield gross produc tion and community respiration rates $(\mathrm{Ra})$ in terms of $\mathrm{g} \mathrm{CO}_{2} \mathrm{~m}^{-2} \mathrm{~h}^{-1}$. These values for GPP and $\mathrm{Ra}$ were then combined with the net change of carbon dioxide $\left(\mathrm{dCO}_{2} / \mathrm{dt}\right.$ in Eq. (2)) to solve for the rate of carbon dioxide absorption (A). This process was repeated for each $24 \mathrm{~h}$ period from January 1 to February 28, 1995. Summary results are presented in Table 1.

\subsection{Estimating seasonal uptake of carbon dioxide by concrete}

In order to determine the amount of carbon dioxide absorbed by concrete during the time period represented by the 3 year biome simulations, it was necessary to make several assumptions. Carbon dioxide scrubbed from the atmosphere by 
chemical precipitation was not accounted for explicitly in the carbon budget but was included in the overall loss to absorption. This was necessary because empirical information on the timing and total amount of carbon dioxide removed by chemical precipitation was not available during model calibration. Long term changes in atmospheric carbon dioxide and oxygen were used to estimate the seasonal absorption of carbon dioxide by concrete. The methods used to calibrate absorption rates for the individual and combined biome models were similar to the diurnal method used to calibrate the Mini model described above (Section 3.2). However, instead of using diurnal curves of oxygen and carbon dioxide, monthly averages were used to quantify the differences between declines in oxygen concentrations and increases in carbon dioxide. Oxygen decreases over time not reflected in carbon dioxide increases were attributed to absorption of carbon dioxide by concrete. As with the diurnal calculations, these estimates were subject to sensor error and incomplete data sets. The carbon dioxide absorption rate values used to calibrate the individual biome models were estimated based on the overall loss term per unit area for the entire enclosure, and the calculated rates of community respiration. It was assumed those biomes with higher respiration rates (and consequently higher carbon dioxide concentrations) would exhibit proportionately higher absorption rates based on first order reaction kinetics. The sum of the

Table 2

Calibration values for the mini model of metabolism inside Biosphere $2^{\text {a }}$

Total area
Total volume
Plant biomass
Oxygen
Carbon dioxide
Soil organic matter
Carbonate materials
Absorbed carbon dioxide
Sunlight
Unused sunlight
Production function
Sunlight used by plants
Production of plants
Production of oxygen
Autotrophic respiration
Plants to soil matter
Oxygen to soil consumers
Decomposition of soil organics
Oxygen to autotrophic respiration
Carbon dioxide from soil
Carbon dioxide from plant respiration
Carbon dioxide to carbonate sinks
Carbon dioxide to photosynthesis
Carbonate release of carbon dioxide

\section{Total area}

Oxygen

Carbon dioxide

Soil organic matter

Sunlight

Unused sunlight

Production function

Production of oxygen

Autotrophic respiration

Plants to soil matter

Decomposition of soil organics

Oxygen to autotrophic respiration

Carbon dioxide from soil

Carbon dioxide to carbonate sinks

Carbonate release of carbon dioxide

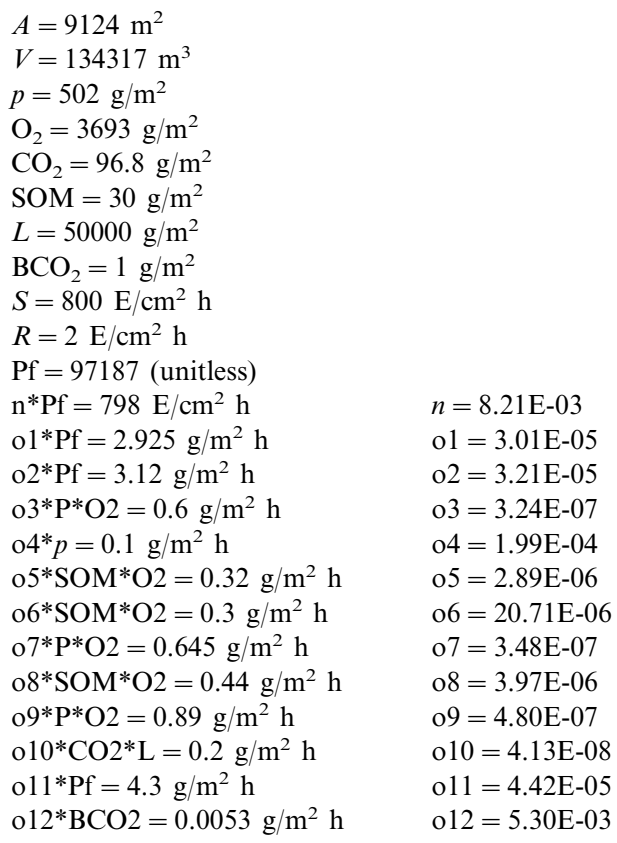

${ }^{\text {a }}$ Letter combinations correspond with expressions in Fig. 2. 
individual biome absorption values is approximately equal to the overall loss term associated with this period of closure.

\subsection{Calibrating the Mini model of metabolism}

Community metabolic rates calculated from diurnal changes in carbon dioxide and oxygen were used to calibrate the Mini model in Fig. 2. The numeric values generated by the diurnal curve analysis were assigned to flowpaths and used to calculate transfer coefficients (Table 2). Numeric values for flowpaths not derived directly from the diurnal curve analysis were obtained using molecular conversion factors and/or estimated for calibration purposes. Initial storage values of carbon dioxide and oxygen were taken from observational data. Starting plant biomass was obtained by averaging observed values (Bierner, 1994) from the individual biomes. Initial values of soil organic matter, calcareous materials, and carbonates were estimated.

The average value of gross oxygen production taken from the diurnal curves was assigned to the flow path designated as $\mathrm{O}_{2}$ in Fig. 2. This value was multiplied by a molecular conversion factor of $30 / 32$ to yield gross production of plant biomass (flow path $\mathrm{O} 1$ in Fig. 2) in terms of $\mathrm{g} / \mathrm{m}^{2}$ per $\mathrm{h}$. The average carbon dioxide fixation rate (flow path $\mathrm{O} 11$ ) was derived directly from the diurnal curve analysis. The average plant respiration rate of oxygen on an hourly basis (flow path O7) was estimated as $20 \%$ of gross oxygen production. This value was multiplied by a molecular conversion factor of $30 / 32$ to obtain a value for respired biomass (flow path O3) and by 44/32 to obtain a value for carbon dioxide evolution (flow path O9) from plants, both in terms of $\mathrm{g} / \mathrm{m}^{2}$ per $\mathrm{h}$. The carbon dioxide absorption rate (flow path O10) was determined directly from diurnal curve analysis. Release of carbon dioxide from bicarbonates (flow path O12) was estimated for calibration purposes only. Soil oxygen demand (flow path O5) was assumed to represent $30 \%$ of hourly community respiration. Oxygen consumption by soil was multiplied by $30 / 32$ to obtain a value for oxidized soil organic matter (flow path O6) and by 44/32 to obtain a value for carbon dioxide emission (flow path O8). The values assigned to flow paths and storages for calibration purposes were later modified for experimental tests.

External sunlight intensity records taken at Biosphere 2 during January and February, 1995 were imported directly into the Mini model computer program (variable $\mathrm{S}$ in Fig. 2). These data were recorded every $15 \mathrm{~min}$ and are the model's driving function. An average value for sunlight intensity was used for calibration. Mini model simulation results were imported into an Excel ${ }^{\mathrm{TM}}$ spreadsheet for graphing.

\section{Results}

For each of the simulation models presented below, an illustration of the biome energy systems diagram will be presented. Steady state simulation results will be 


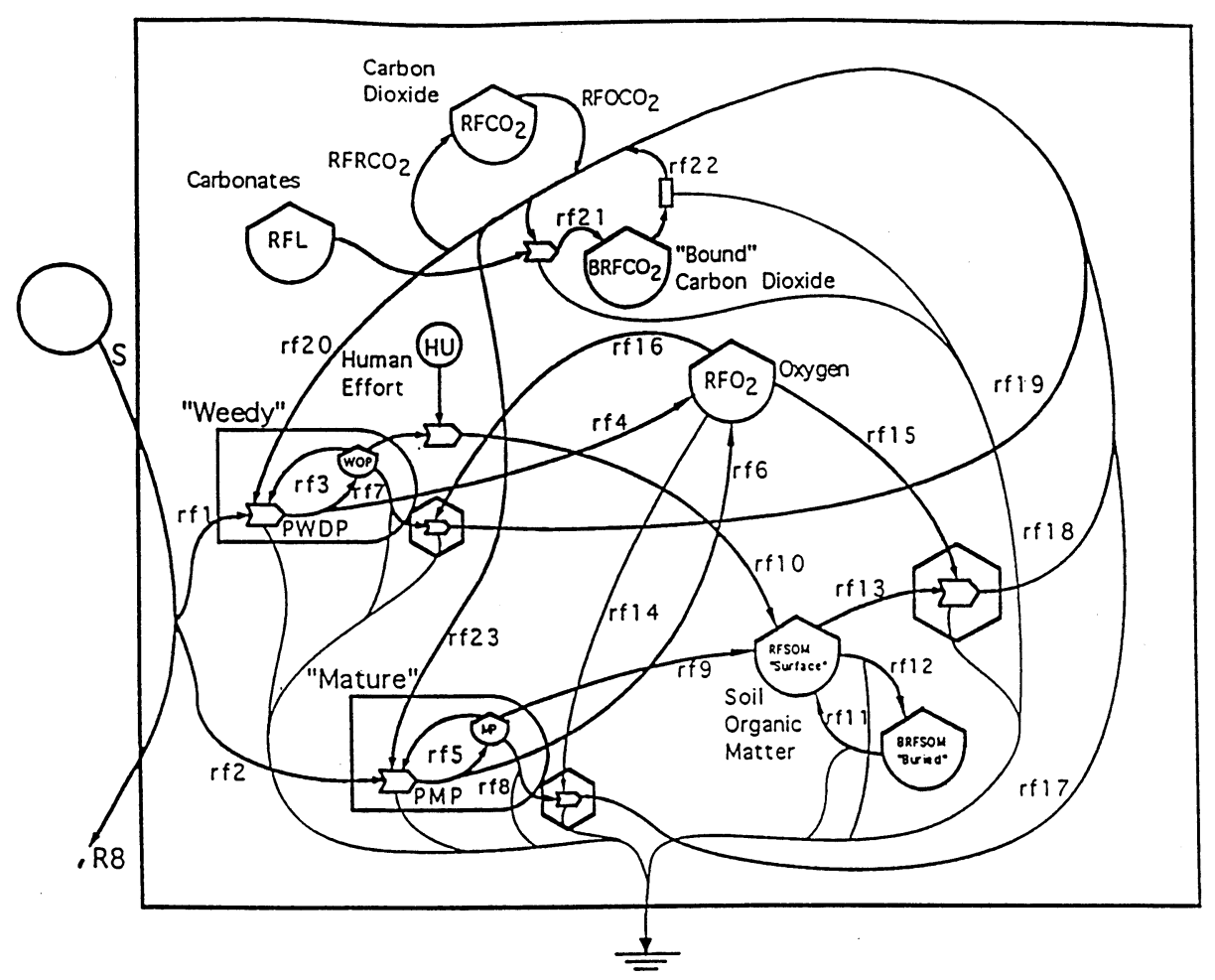

Fig. 4. Energy system diagram used to simulate the rainforest biome inside Biosphere 2 .

discussed and compared with results of experimental changes in initial conditions from three individual biome models, the Combined Biome model, and the Mini model. Changes in atmospheric gases produced by individual biome models are not intended to represent values for the entire Biosphere 2 enclosure. Rather, they are the changes one might expect if these biomes were isolated from other biomes. Only simulations of the Combined Biome model and the Mini model of metabolism are intended to represent system wide values.

\subsection{Rainforest biome}

\subsubsection{Systems diagram}

The model and equations for the rainforest biome are illustrated with Fig. 4. Transfer coefficients are represented by lower case letter and number combinations next to material pathways. Storages are identified by capital letter codes.

Primary production in the rainforest model is divided between two units that compete for sunlight $(\mathrm{S})$ and carbon dioxide $\left(\mathrm{RFCO}_{2}\right)$. The unit to withdraw first from sunlight (PWDP) represents successional, 'weedy' species. The other production unit (PMP) is intended to represent the larger, 'mature' plants imported into 
the Biosphere 2 rainforest biome before closure. The gross production: respiration ratio of 'weedy' successional species is 1.7 , for mature plants the ratio is 1.4. Human effort (HU) reduces the biomass of weedy, successional species (WDP), and causes an increase (rf10) in soil organic matter. Soil organic matter in the rainforest biome is divided into two reservoirs: surface soil organic matter (RFSOM) subject to immediate oxidation, and 'buried' soil organic matter (BRFSOM).

\subsubsection{Rainforest calibration simulation}

The result of the rainforest simulation with calibrated values is presented with Fig. 5. Gross production and community respiration of oxygen are closely matched, but the net decrease in oxygen indicates however that community respiration remains higher than gross production throughout the simulation. Oxygen decreases from 21 to $18 \%$ during the first 6 months of simulation primarily due to soil respiration. Plant biomass decreases slightly during the first 6 months of low sunlight, then continues to increase over the 3 year period.

\subsubsection{Effect of carbon dioxide absorption}

The simulation in Fig. 6 was run without absorption by calcareous materials, causing atmospheric carbon dioxide to increase to a maximum value of $10 \%$ during the winter, low light conditions of the third year. This increase in carbon dioxide is matched by an equivalent decrease in atmospheric oxygen: an expected result considering the model was calibrated with respiration quotients of one.

\subsubsection{Changing the ratio of community gross to net production}

For the simulation run in Fig. 7, the effect of human intervention on primary production was investigated. The human effort to remove successional vegetation was increased from a normalized, calibration value of $1-1.5$, effectively changing

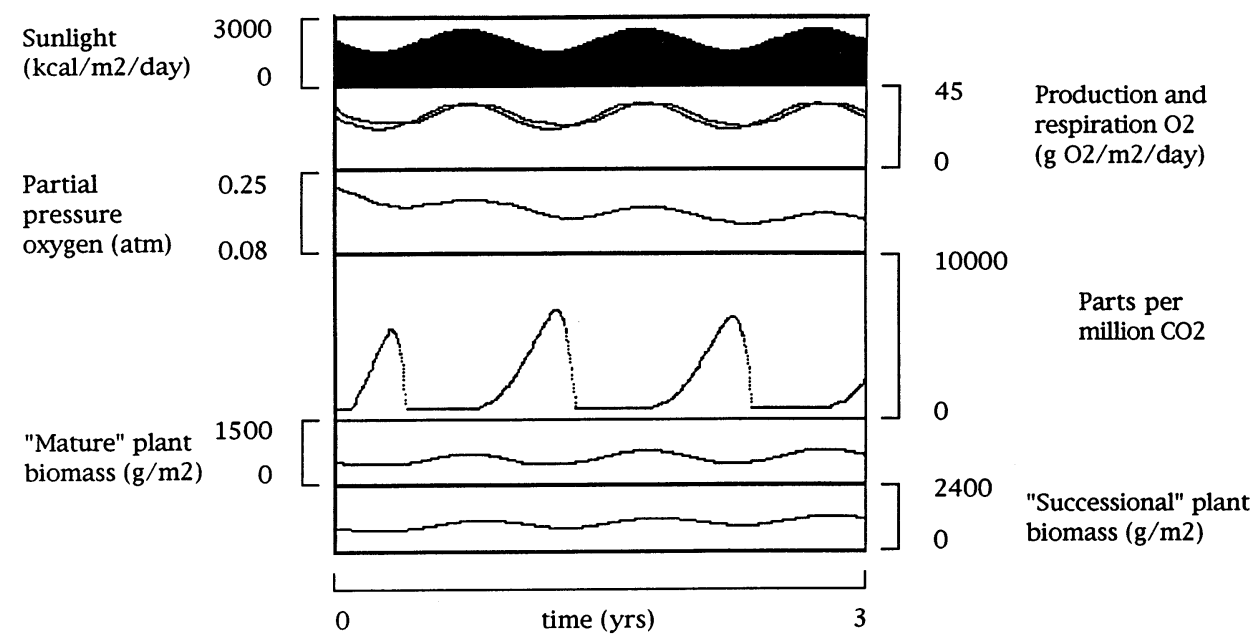

Fig. 5. Baseline simulation of the rainforest biome model (Fig. 4) using calibration values. 


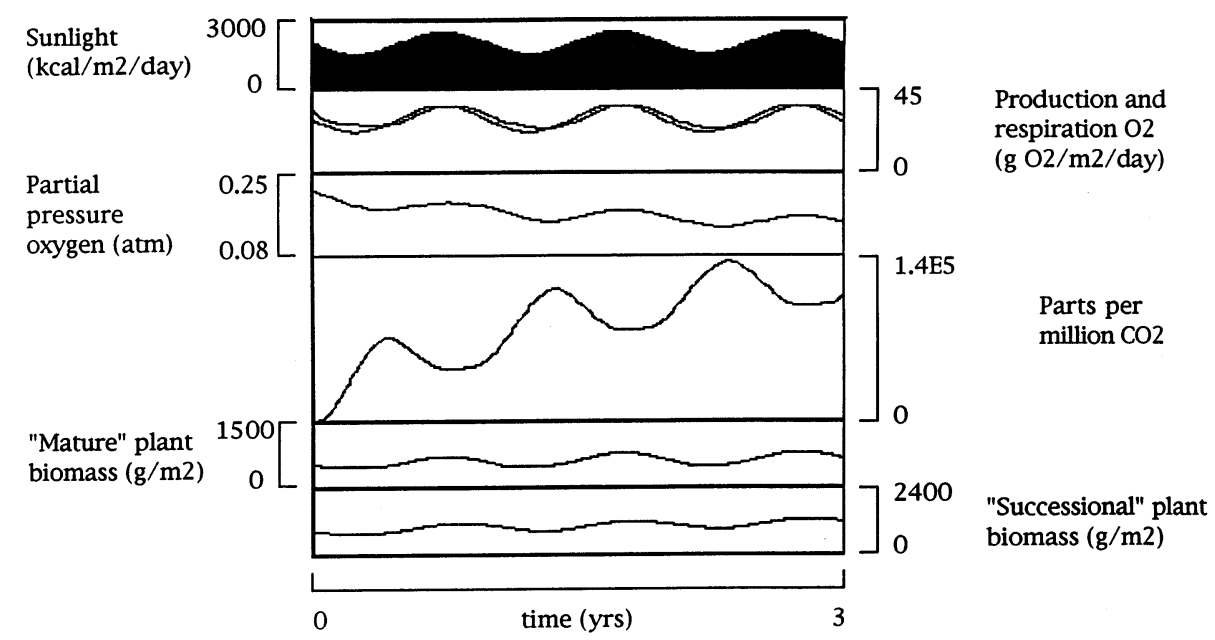

Fig. 6. Simulation of the rainforest biome model without the absorption of carbon dioxide by calcareous materials.

the ratio of community gross production to respiration by increasing the proportion of mature plants in the total rainforest biomass. This simulation also did not include carbon dioxide absorption so any effect produced by human intervention would not be obscured.

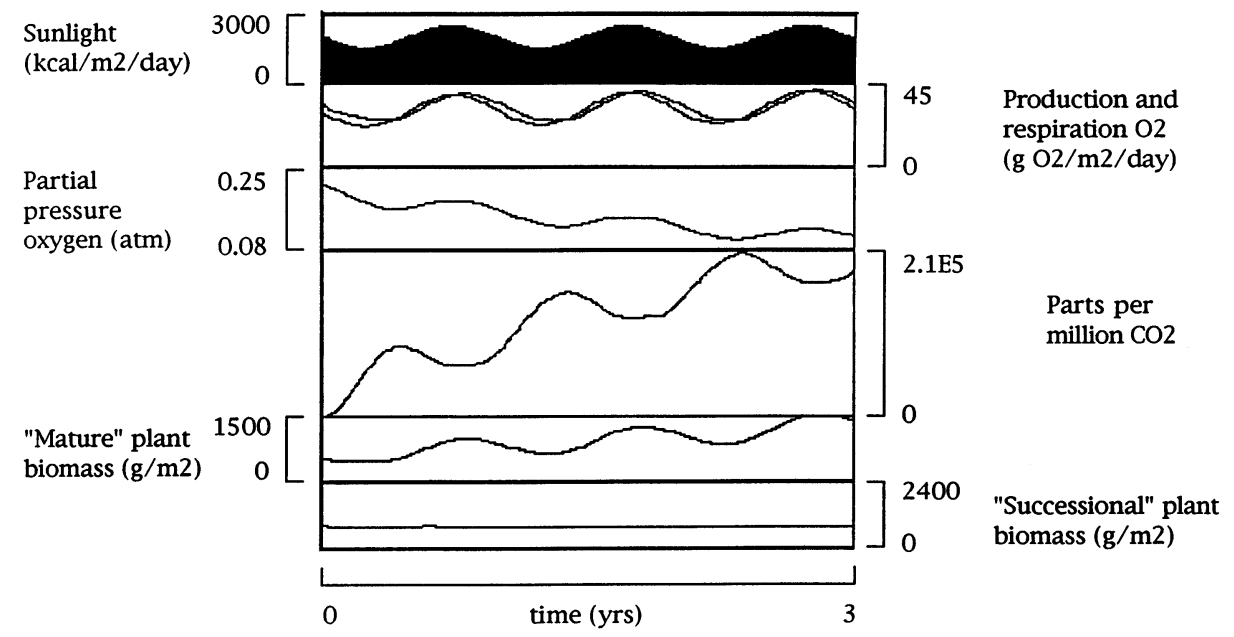

Fig. 7. Simulation of the rainforest biome with increased human effort to remove successional (i.e. weedy) plant growth, effectively changing the net production rate of the community in the biome. 


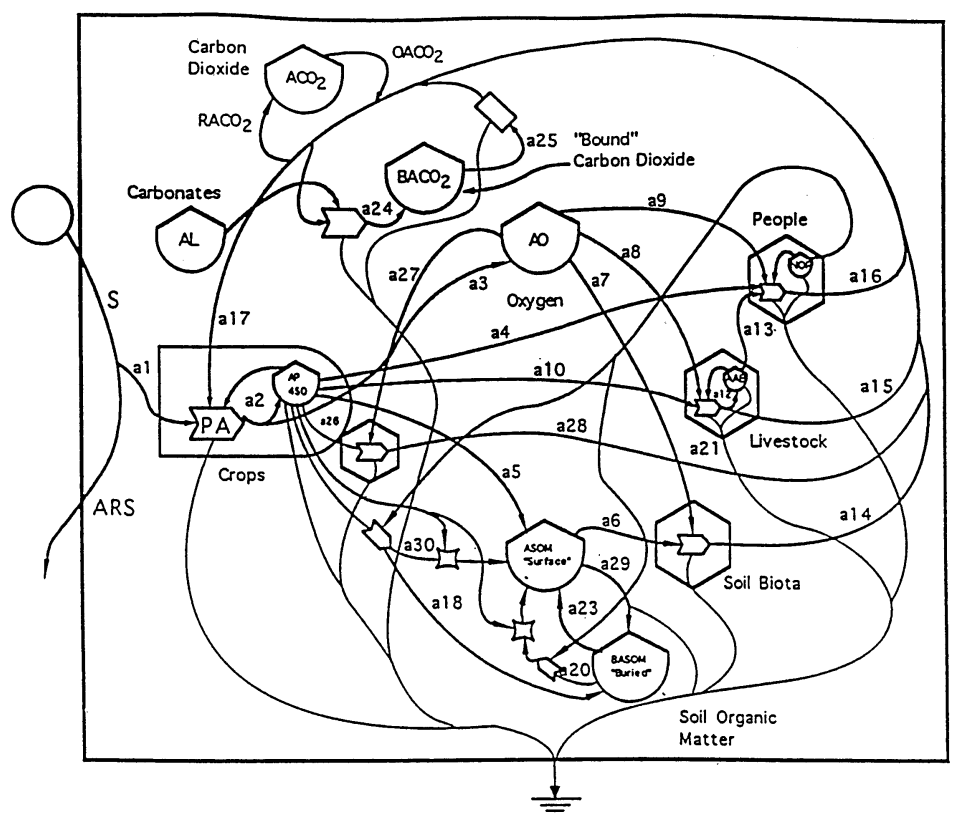

Fig. 8. Energy system diagram used to simulate the agriculture biome inside Biosphere 2 .

\subsection{Agriculture biome}

\subsubsection{Agriculture calibration simulation}

The Agriculture biome in Biosphere 2 was simulated with the model in Fig. 8. The Agriculture biome model run under calibration values is presented with Fig. 9. Simulated harvests produce incremental decreases in crop biomass, represented as breaks in biomass concentrations in the display graphs. In this simulation, the upper limit of crop biomass that triggers harvest is reached on average twelve times per year, and increases during each successive year. This does not imply twelve crops were grown and harvested from all plots during each year of closure. Only $\approx 10 \%$ of biomass (or total production) was removed during each event, representing the harvesting of mature plants.

\subsubsection{Effect of one-half the original soil organic matter}

The simulation graph in Fig. 10 illustrates the effect of decreasing by one-half the initial amount of agriculture soil organic matter. The lack of soil organic matter during this run lowers community respiration rates below gross production, causing a net increase in atmospheric oxygen concentrations and lower carbon dioxide concentrations. The lack of carbon dioxide produced from respiration appears to also decrease crop development, and replanting is triggered only seven times in 3 years. This result holds implications for carbon sources and requirements for food production inside Biosphere 2. 


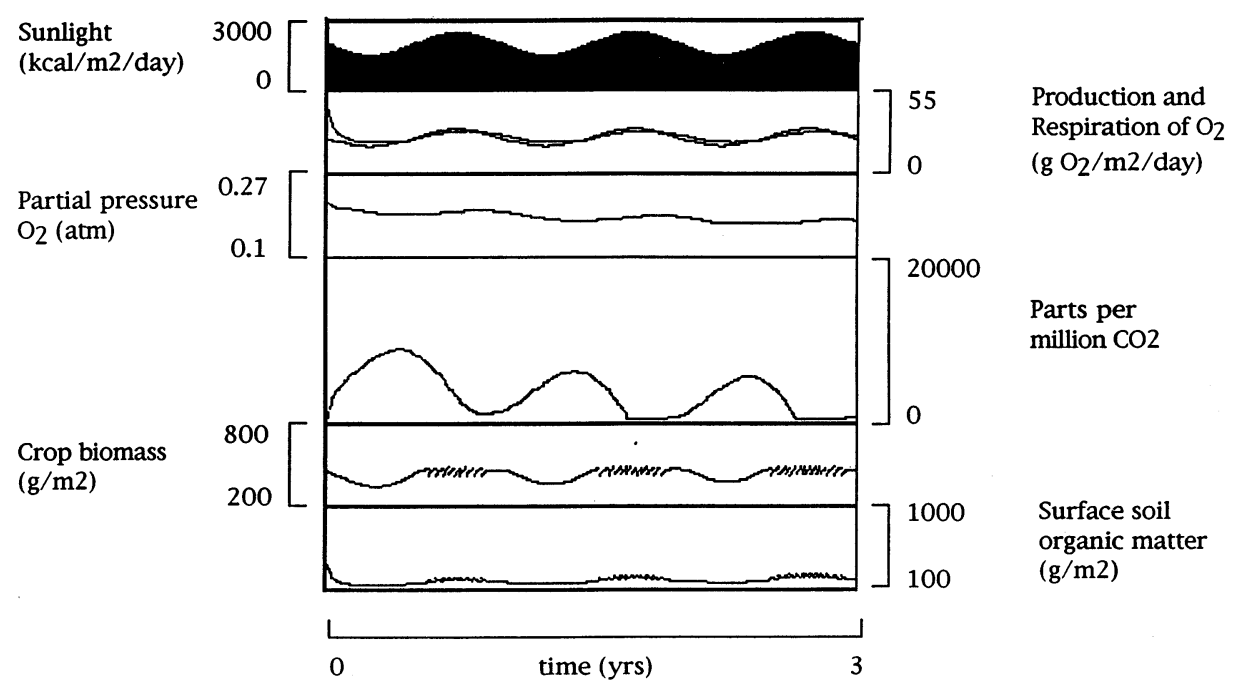

Fig. 9. Simulation of the Agriculture biome model using calibration values.

\subsection{Ocean biome}

\subsubsection{Systems diagram}

The model and equations used to simulate the ocean biome is illustrated in Fig. 11.

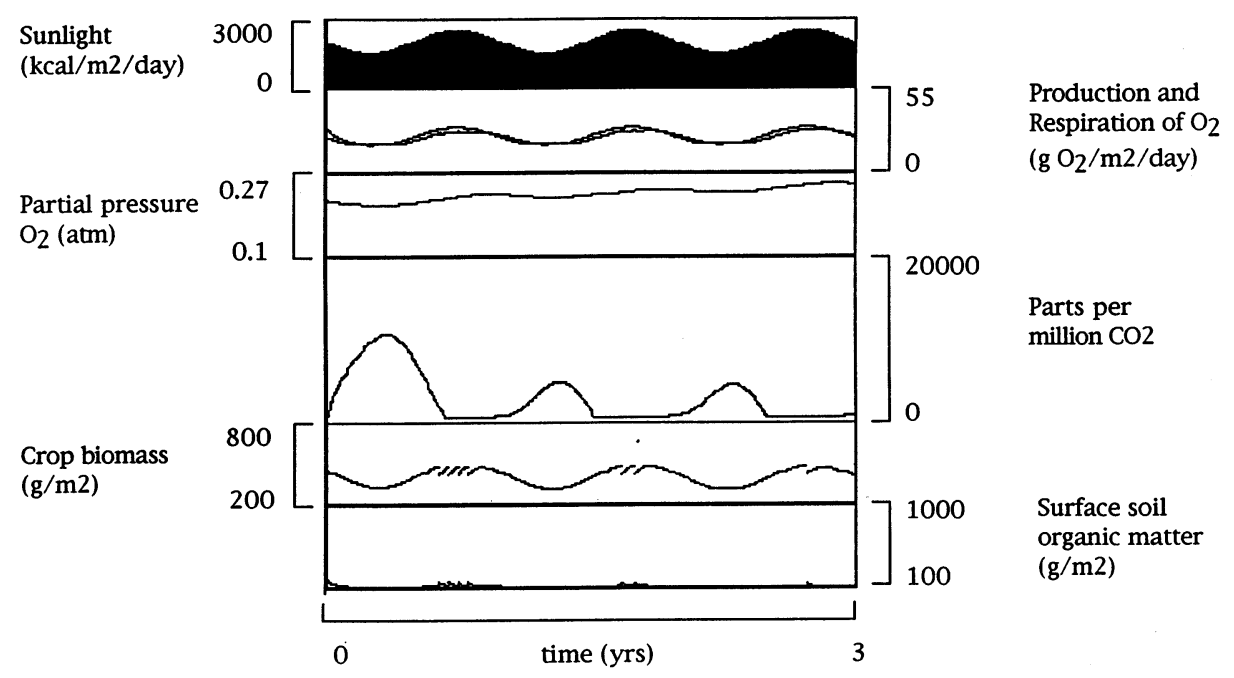

Fig. 10. Simulation of the agriculture biome model with one half the original soil organic matter concentration. 


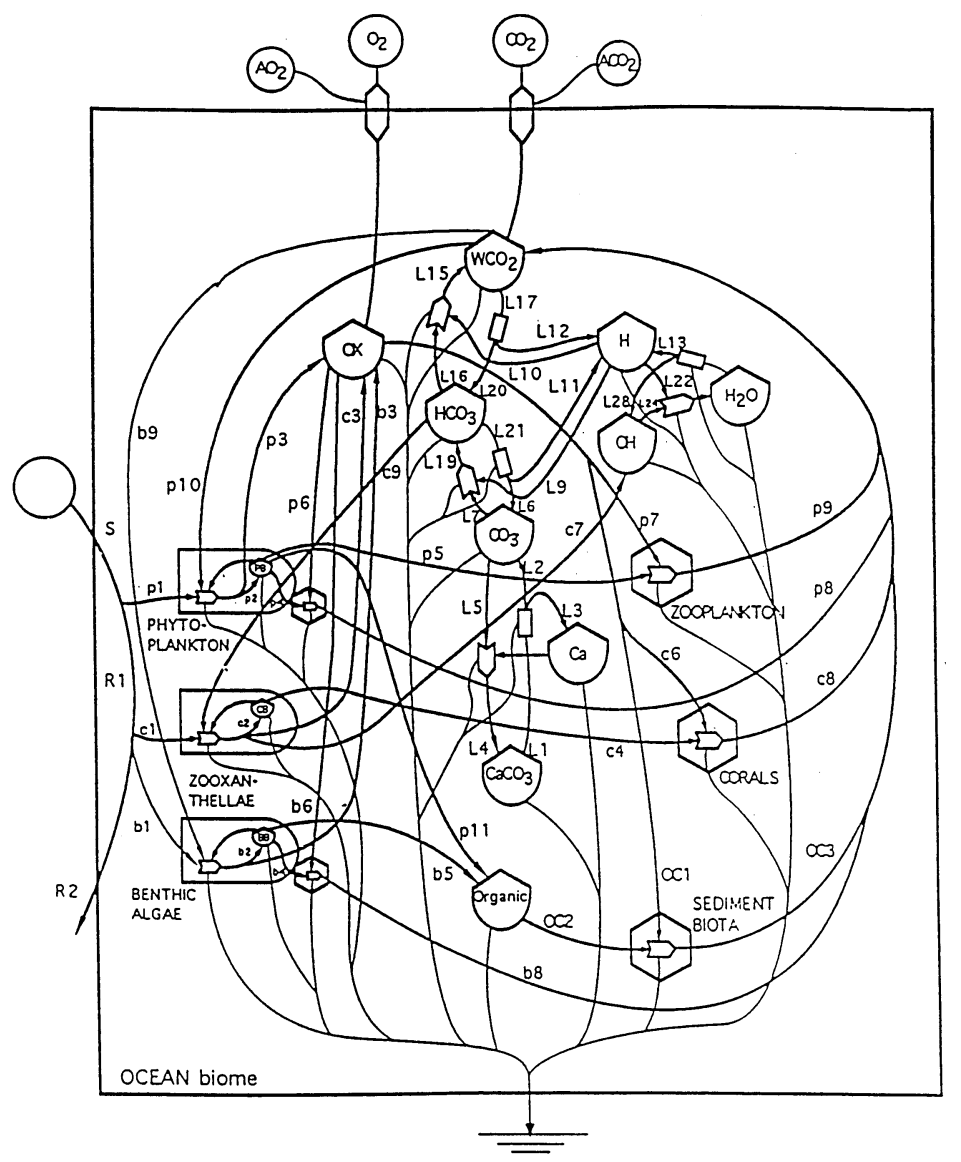

Fig. 11. Energy system diagram used to simulate the ocean biome inside Biosphere 2.

The carbonate equilibria illustrated in the top half of the diagram simulates the reactions between dissolved carbon dioxide and calcium carbonate. The transfer coefficients used to calibrate the carbonate equilibria exchanges do not represent reaction rates. Rather, they are calculated to maintain concentrations of chemical species at equilibrium relative to storages with longer turnover times. Atmospheric oxygen and carbon dioxide concentrations are simulated with sine and cosine functions, respectively, with values oscillating around those observed inside Biosphere 2. Temperatures are held constant in this model. Biomass, production and respiration rates of biological processes were estimated primarily from literature (Adey, 1991).

\subsubsection{Ocean model calibration simulation}

The ocean biome model (Fig. 11) is more complex than the other individual biome models, reflecting characteristics of the aquatic medium. Simulation results 
were most sensitive to air-water gas exchange rates, sunlight intensities, and the proportion of phytoplankton to zooxanthellae production rates. Results suggest light is the limiting factor in photosynthesis in this biome and that short term ocean $\mathrm{pH}$ is determined primarily by autotrophic production rates. Fig. 12 illustrates the calibration run of the ocean biome model. The model is successful in reproducing observed diurnal changes in ocean $\mathrm{pH}( \pm 0.02)$ using the kinetic based representation of the carbonate system.

\subsubsection{Low light and high atmospheric carbon dioxide}

Fig. 13 illustrates the effect of low light conditions and high levels of atmospheric carbon dioxide on the ocean biome. Differences from the calibration run include an increase in community respiration, a decrease in gross primary production, a lower $\mathrm{pH}$, increased dissolution of calcium carbonate, and a decrease in coral biomass.

\subsubsection{Effect of bicarbonate additions on ocean $p H$}

The management practice of adding bicarbonate solutions to the ocean biome to increase $\mathrm{pH}$ was simulated and is presented in Fig. 14. During day 8 of the simulation, $\approx 10 \mathrm{~g} / \mathrm{m}^{3}$ of bicarbonate are added to the ocean water. Ocean $\mathrm{pH}$ increases immediately after the bicarbonate addition, and the final value of $\mathrm{pH}$ at the end of this simulation (7.96) is higher than the end value (7.94) of the simulation in Fig. 13.

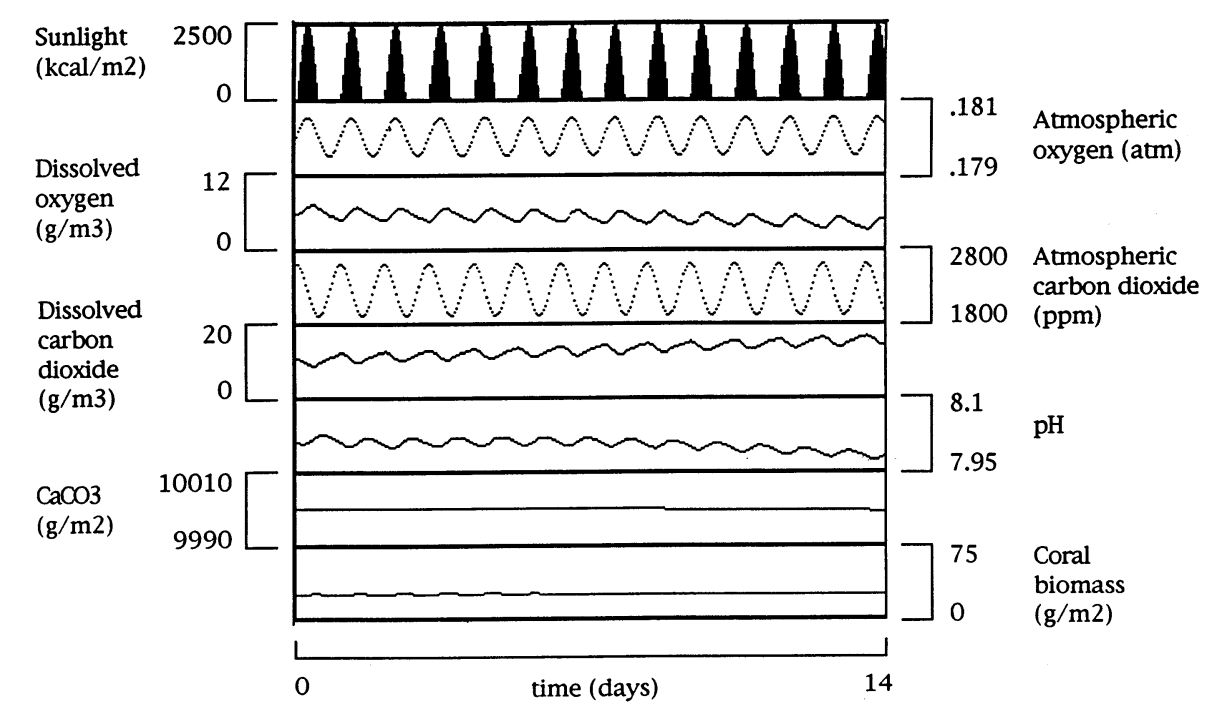

Fig. 12. Baseline simulation of the ocean biome model with calibration values. 


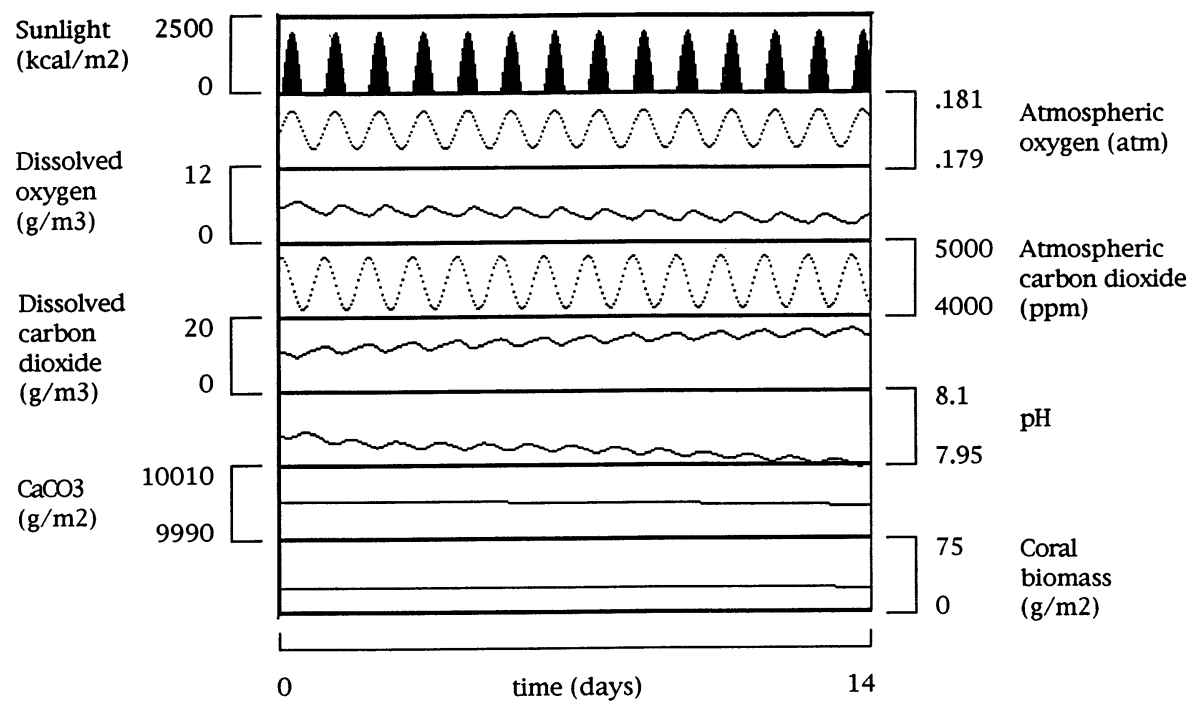

Fig. 13. Simulation of the ocean biome model under low sunlight and high atmospheric conditions.

\subsection{Savannah, wetland, and desert biome models}

Simulation models for the desert, savannah, and wetland biomes were also developed for this research. These models are similar in complexity to the other terrestrial biome models, with some slight modifications to more accurately reflect

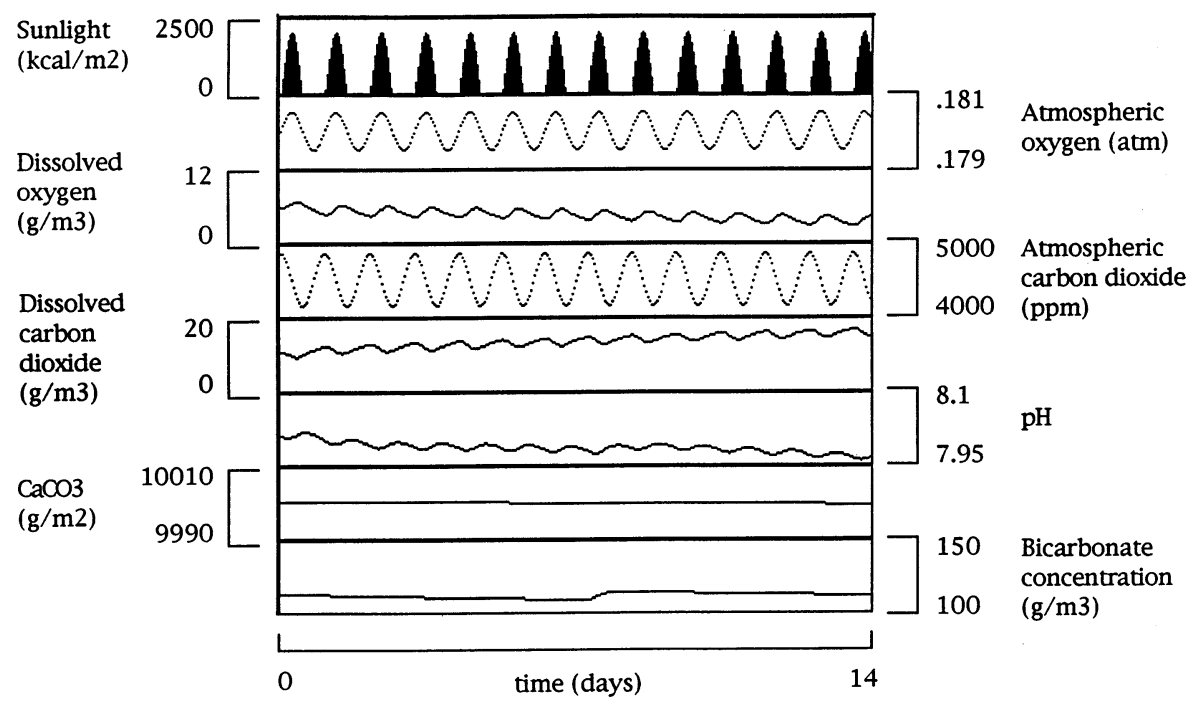

Fig. 14. Simulation of the ocean biome model showing the temporary effect of bicarbonate additions on $\mathrm{pH}$ and calcium carbonate concentrations. 
their contribution and effects on the combined metabolism. For example, the desert biome is calibrated with a water cycle that causes photosynthesis to peak during periods of low sunlight. This is intended to represent a management strategy used to control carbon dioxide during winter conditions. Results from these individual biome models are not included in this paper, but their effect on the Combined Biome model will be discussed.

\subsection{Combined Biome model}

\subsubsection{Systems diagram}

To create a model representative of the entire Biosphere 2 enclosure, the individual biome models were linked into a comprehensive program to form the Combined Biome model. A simplified systems diagram of the Combined Biome model showing atmospheric linkages is illustrated with Fig. 1. The power source $(\mathrm{Pu})$ driving the exchange between the biomes represents the mechanical circulation of air within Biosphere 2. The biomes do not compete for light, so each biome has a separate (but equal) sunlight function. The individual biome models are symbolized by the squares in this diagram. All the elements of the individual biome models are preserved in this Combined Biome model program. Oxygen and carbon dioxide reservoirs from each individual biome are joined by exchange functions. Transfer rates of atmospheric gases are proportional to differences in concentrations.

The complete ocean model was not included in the Combined biome model simulations. The configuration was modified after demonstrating the ocean's effect on the overall atmosphere was unrecognizable at the scale presented. The set of experiments with the Combined Biome model described below involve removing the contribution of an individual biome to compare with the model calibration run. During these experiments, the impact of each biome on the overall metabolism is revealed.

\subsubsection{Combined Biome calibration simulation}

Fig. 15 illustrates the simulation of the Combined Biome model with calibrated values. In the following Combined Biome simulation graphs, production and respiration rates, oxygen and carbon dioxide concentrations from all individual biomes are summed and divided by the entire area of Biosphere 2 to represent community values.

Community gross production and respiration rates are closely matched throughout the calibration run. As a result of high soil respiration rates during the initial period of low light, carbon dioxide increases, and oxygen decreases during the first 4 months of simulation. Oxygen decreases to $15.2 \%$ after 480 days of simulation. Actual oxygen concentrations decreased in Biosphere 2 after the same time period to $14.2 \%$.

\subsubsection{Effects of individual biomes on community metabolism}

The simulations illustrated with Figs. 16-19 were produced with the Combined biome model after removing the contribution of selected biomes. The results of 


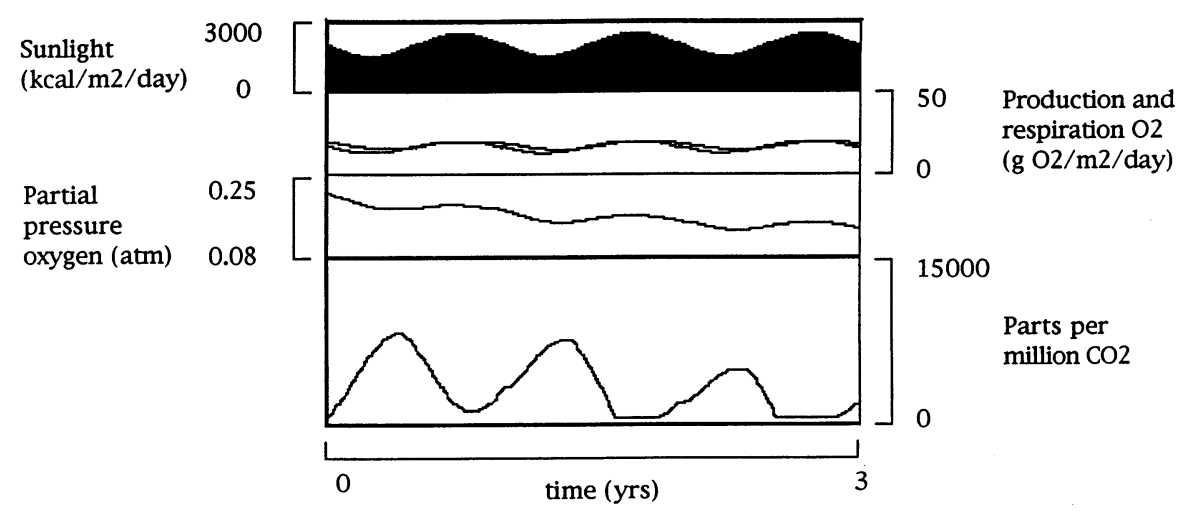

Fig. 15. Simulation of the Combined Biome model (Fig. 1) with calibrated conditions showing community gross production, respiration, oxygen, and carbon dioxide in Biosphere 2 under materially closed conditions.

these simulations give an indication of each biome's contribution to the collective metabolism inside Biosphere 2.

Fig. 16 illustrates the community metabolism of Biosphere 2 without the contribution of the rainforest biome. When compared to the run in Fig. 15, rates of gross production and respiration of oxygen are $1 / 2$ calibration levels. The simulation identifies the rainforest biome as a net oxygen producer over the long term. Per unit area, the rainforest has a disproportionate effect on the overall metabolism, considering it represents only $20 \%$ of the total area of Biosphere 2 (not including the expandable lungs), and yet may be responsible for as much as $50 \%$ of the community metabolic rate.

Fig. 17 illustrates the changes in the Combined Biome simulation that occur without the contribution of the agriculture biome model. The relative impact of the agriculture biome on atmospheric composition in Biosphere 2 may be higher than any biome, and is responsible for as much as $30-45 \%$ of the variation in

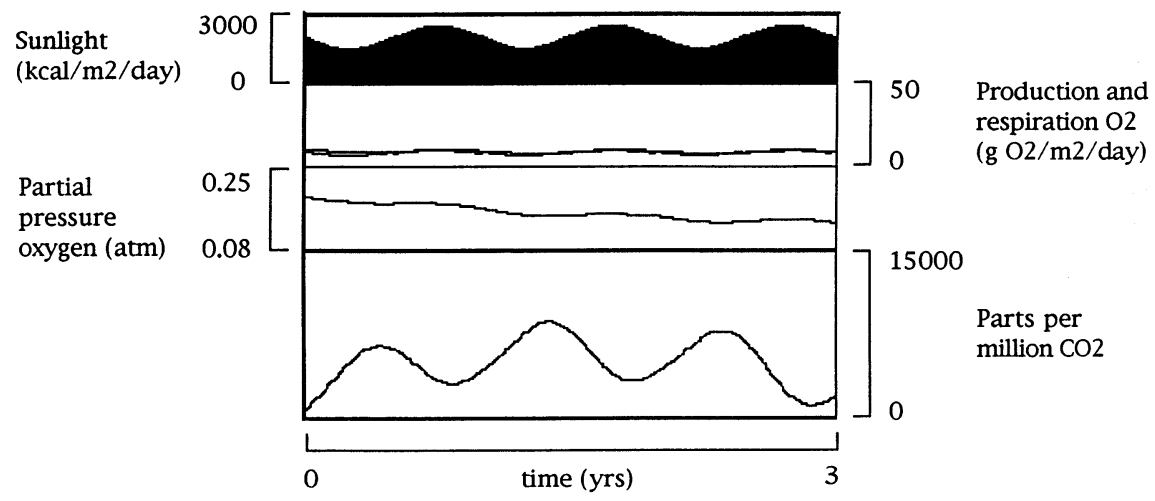

Fig. 16. Combined Biome model simulation without the contribution of the rainforest biome. 


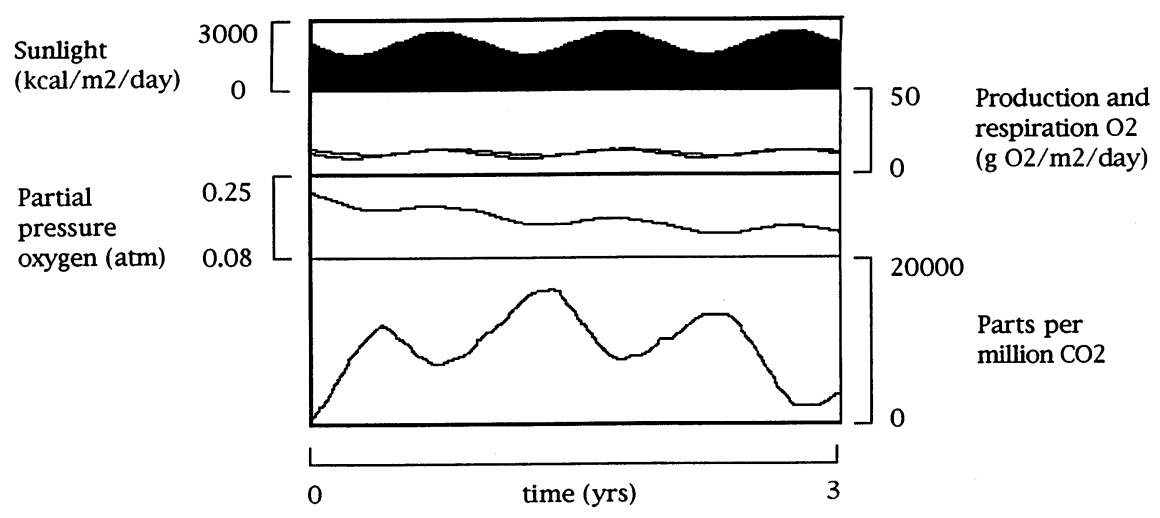

Fig. 17. Combined Biome model simulation without the contribution of the agriculture biome.

atmospheric composition. This result assumed the agriculture biome to be under constant cultivation throughout the simulation period with harvesting events occurring 12 times per year.

Fig. 18 illustrates the simulation of the Combined Biome model without the contribution of the savannah and wetland biomes. Rapid biomass turnover and high soil respiration rates may cause these biomes to be net producers of carbon dioxide in the long term. Results indicate these two biomes may be responsible for as much as $30-40 \%$ of the variation in atmospheric composition.

Fig. 19 illustrates the changes in the Combined Biome model that occur without the contribution of the desert biome. The primary impact of the desert biome in the Combined Biome model simulation occurs during low light periods, when it may be responsible for $5-30 \%$ of overall carbon dioxide changes. This simulation also indicates the desert biome is a source of carbon dioxide during the summer months.

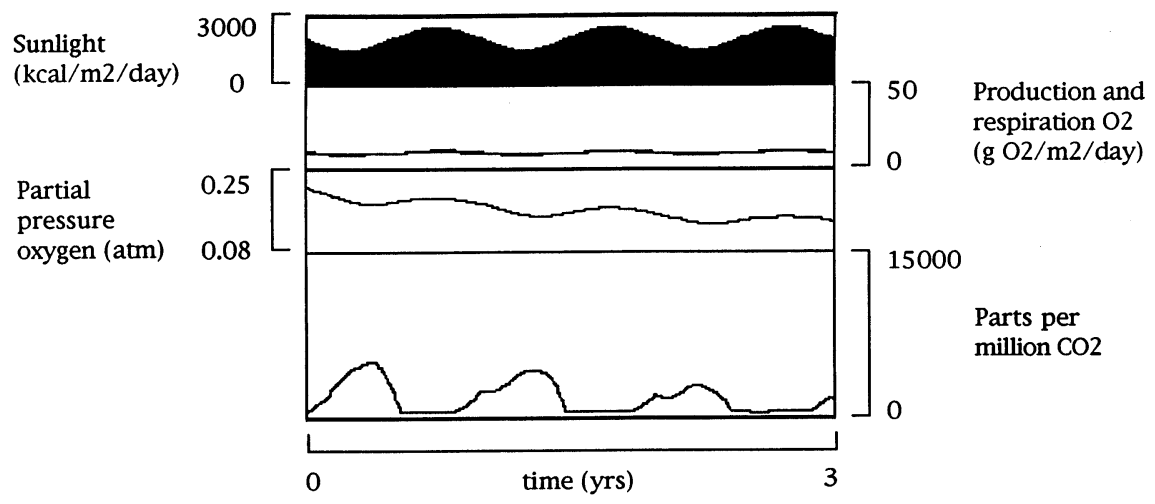

Fig. 18. Combined Biome model simulation without the contributions of the savannah and wetland biomes. 


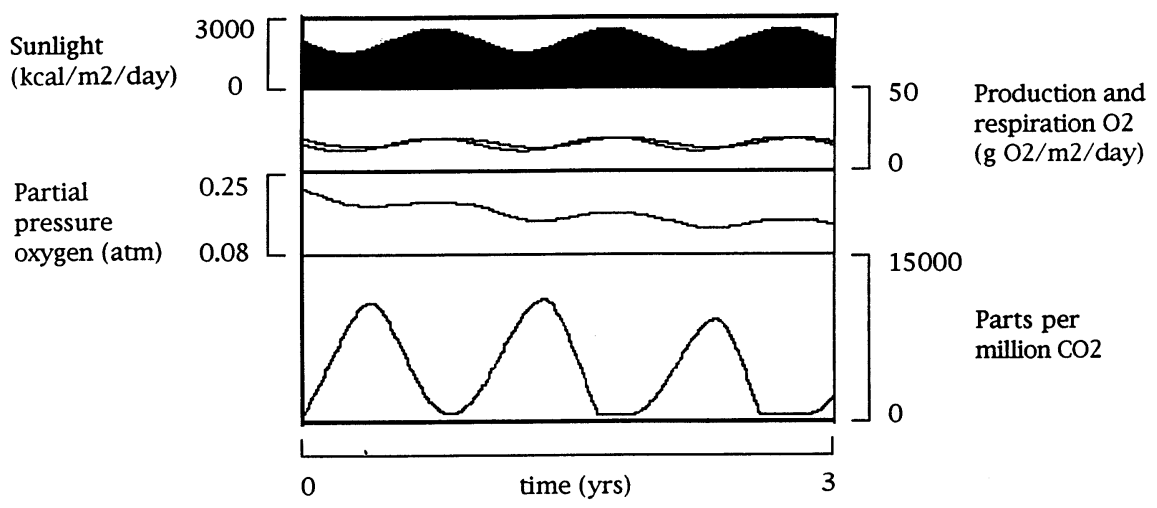

Fig. 19. Combined Biome model simulation without the contribution of the desert biome.

\subsection{Mini model of Biosphere 2}

\subsubsection{Metabolism calculations}

Analyses of diurnal pressure changes in oxygen and carbon dioxide from inside Biosphere 2 during the period between January and February, 1995 yield the following results: community gross primary production averaged $3.12 \mathrm{~g} \mathrm{O}_{2} \mathrm{~m}^{-2}$ $\mathrm{h}^{-1}$ during an average $8.3 \mathrm{~h}^{\text {day }^{-1}}$ above the photosynthetic compensation point, and respiration averaged $0.97 \mathrm{~g} \mathrm{O}_{2} \mathrm{~m}^{-2}$ per $\mathrm{h}$ during $15.7 \mathrm{~h}$ below the compensation point. The absorption rate of carbon dioxide by calcareous materials averaged $0.2 \mathrm{~g} \mathrm{CO}_{2} \mathrm{~m}^{-2} \mathrm{~h}^{-1}$. This absorption rate, however, is subject to error associated with the baseline data set. Severinghaus (1994) measured carbon dioxide absorption rates from isotope changes in structural concrete between 0.23 and $0.31 \mathrm{~g} \mathrm{CO}_{2} \mathrm{~m}^{-2}$ $\mathrm{h}^{-1}$. An example of observed diurnal oxygen changes are presented in Fig. 20. Error associated with sensor noise forced the removal of $\approx 17 \%$ of the data from the metabolism calculations before calibrating the Mini model.

\subsubsection{Mini model simulation results}

External light intensity (Fig. 21) is imported into the Mini model for short term simulations. Simulation time in this model is 18 days. Comparisons with Fig. 22 reveal community gross primary production rates follow light intensity changes. Simulated rates of community respiration over the same period are presented in Fig. 23.

A comparison of observed and simulated atmospheric carbon dioxide concentrations is presented in Fig. 24. Simulated changes in carbon dioxide concentrations exhibited slightly smaller diurnal amplitudes than observed changes.

\subsubsection{Absorption of carbon dioxide}

One experiment with the Mini model included removing the absorption of carbon dioxide by concrete. The result of this change in initial conditions is presented in Fig. 25. The model estimates absorption of carbon dioxide is responsible for $7.3 \%$ of the average daily decrease in carbon dioxide during sunlight hours. 


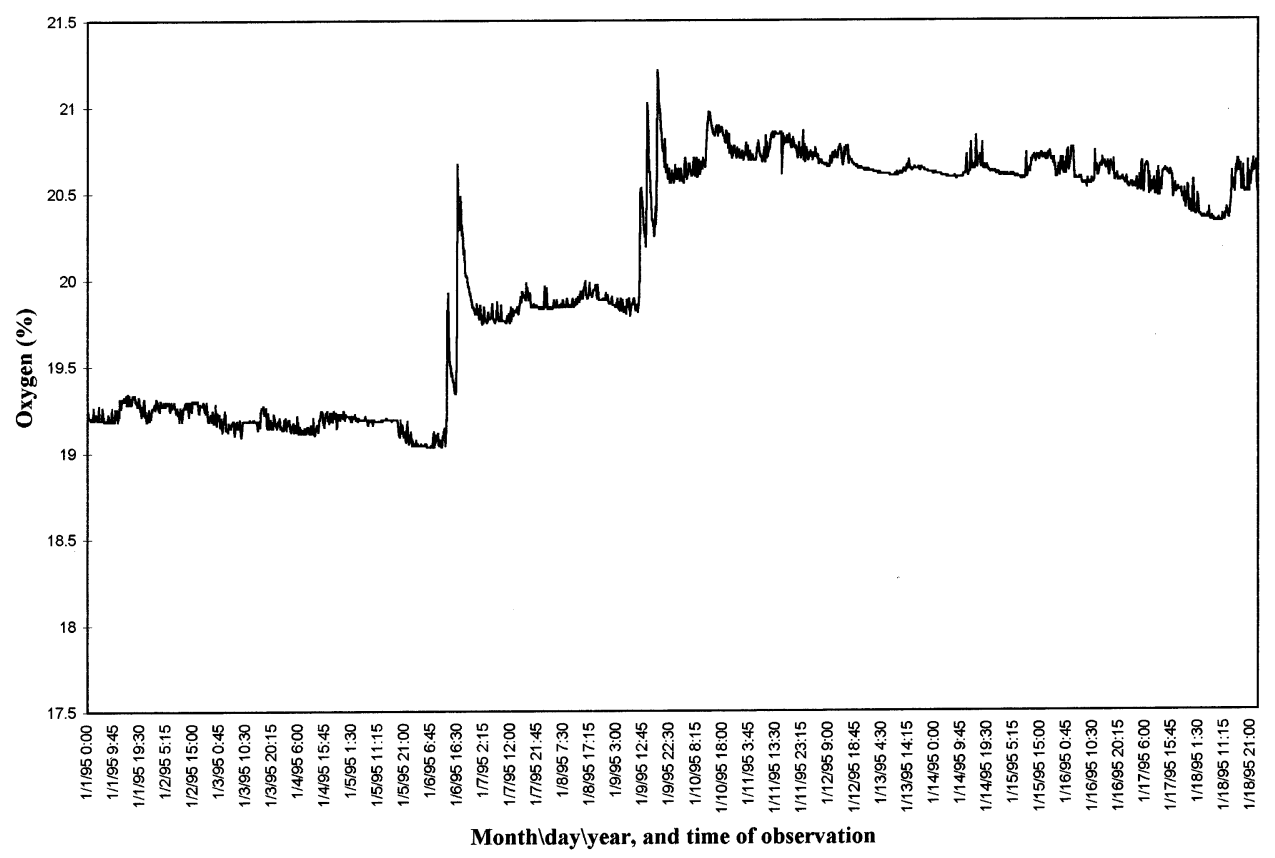

Fig. 20. Example of sensor noise in diurnal oxygen data in Biosphere 2.

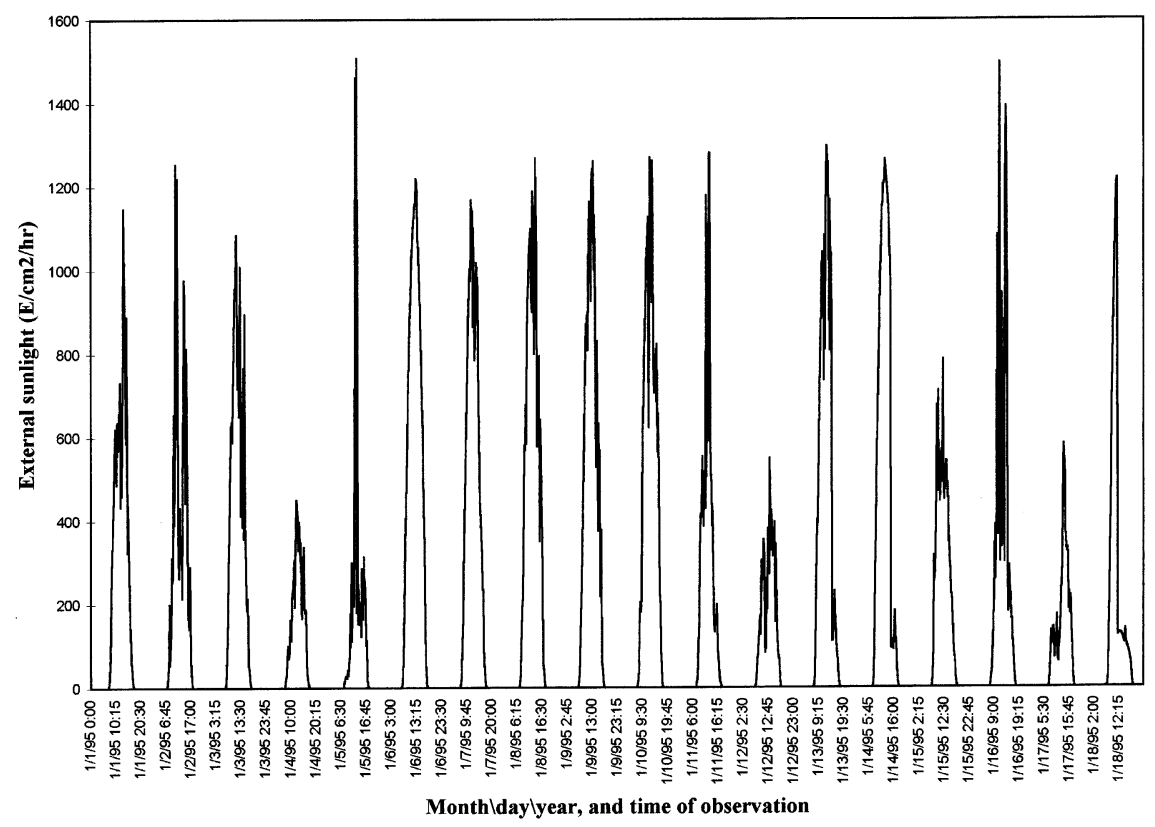

Fig. 21. Observed outside ambient light conditions at Biosphere 2 during Mini model simulation period. 


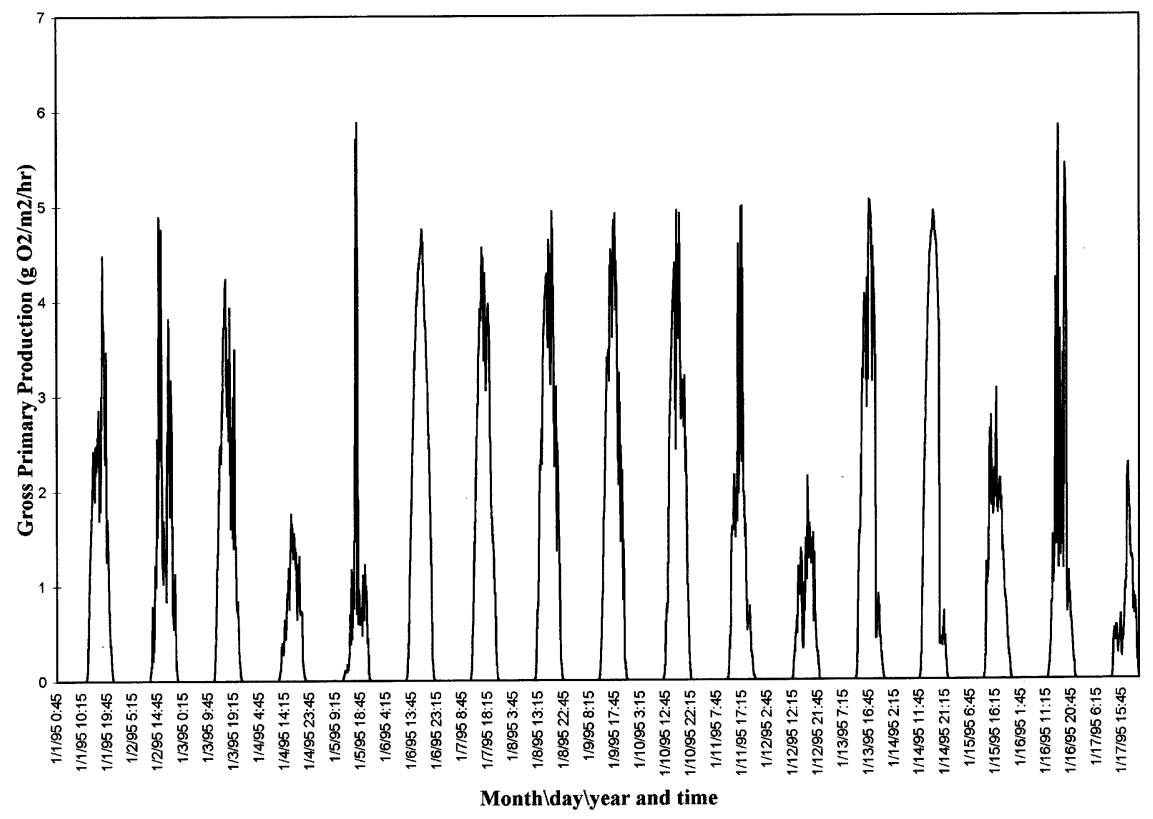

Fig. 22. Simulated rates of gross primary production inside Biosphere 2 produced by the Mini model of metabolism depicted in Fig. 3.

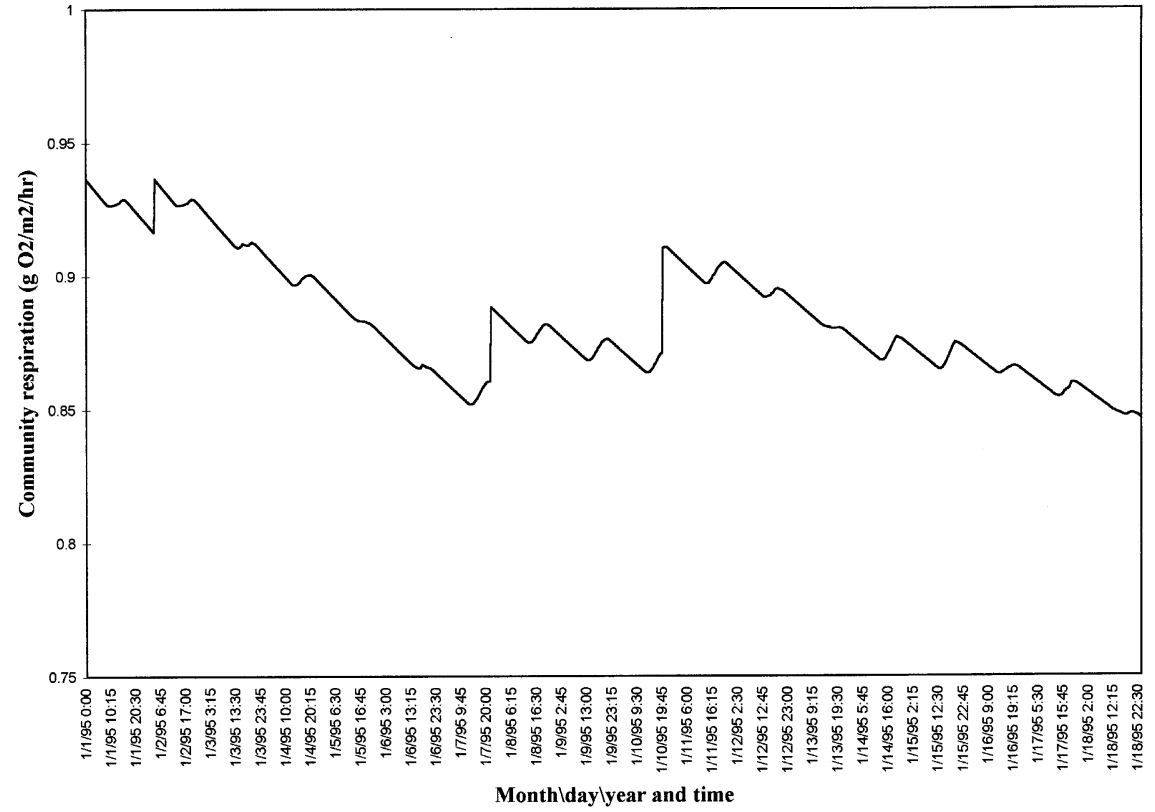

Fig. 23. Mini model simulated rates of community respiration inside Biosphere 2. 


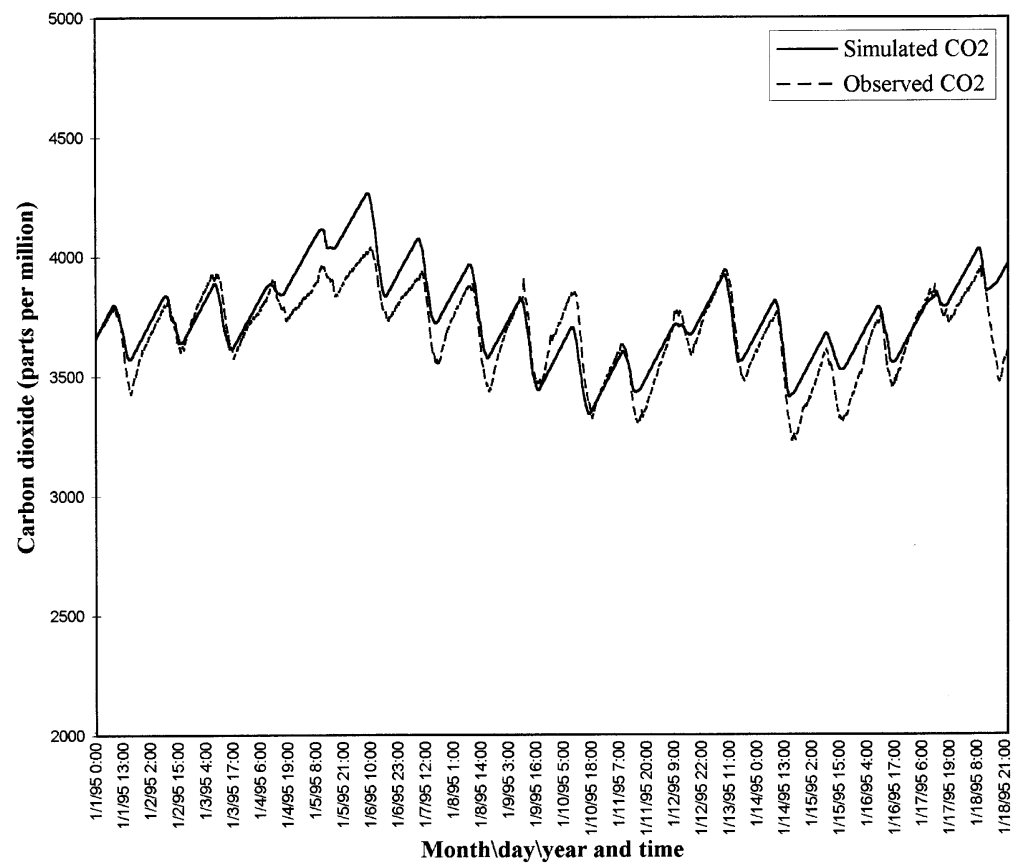

Fig. 24. Mini model simulated versus observed diurnal curves of carbon dioxide from baseline calibration values.

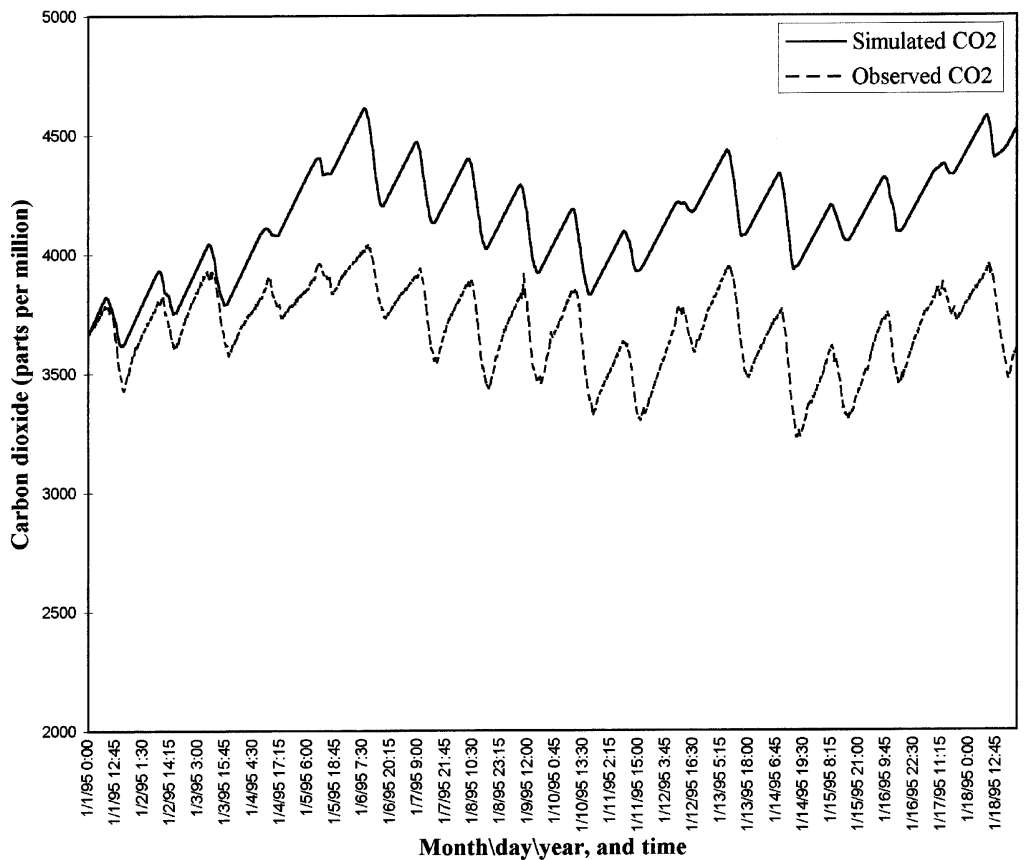

Fig. 25. Mini model simulated diurnal changes in carbon dioxide without absorption versus observed values. 


\section{Discussion}

\subsection{Comparisons of simulation results to observed conditions}

Using diurnal curve analyses and sunlight intensity data to calculate transfer coefficients increases the accuracy of the Mini model with respect to interior conditions and enables direct comparisons of simulation results with observed values (Fig. 24). The primary benefit of the Mini model may be in short term simulations with frequent recalibrations to reflect changing internal and external input conditions. An accurately calibrated Mini model from seasonally representative diurnal curves may help to investigate the responses of interior conditions to experimental manipulations.

Result from the individual and Combined Biome model simulations are intended to investigate changes in community metabolism given variable, initial operating conditions and to illustrate the contribution of individual biomes to the overall metabolism. Sensitivity analyses provide insight into the primary controlling factors of long term community metabolism inside Biosphere 2 and also help to identify feedback mechanisms. Under the current format, the steady state simulations of the biome specific models have less predictive ability than the Mini model. Logistical difficulty in obtaining data on reservoir sizes, process rates, and human manipulations during the initial closure period reduced the accuracy of transfer coefficients and qualifies direct comparisons to observed values.

\subsection{Calibrating the simulation models}

Error associated with oxygen sensor noise and its effect on calculated rates of carbon dioxide absorption rates were important factors causing deviations from observed values after 18 days of the Mini model simulation. An attempt was made to compensate for sensor error by removing calculated absorption rates above \pm 4 $\mathrm{g} \mathrm{CO}_{2} \mathrm{~m}^{-2} \mathrm{~h}^{-1}$ from the data set before calibration. Negative absorption rates $>-4.0 \mathrm{~g} \mathrm{CO}_{2} \mathrm{~m}^{-2} \mathrm{~h}^{-1}$ were interpreted as a release of carbon dioxide from calcareous material bicarbonate equilibria, and used to estimate an average release rate for calibration purposes only. It is unclear, however, whether negative absorption values represent actual releases of carbon dioxide or sensor error. Current analyses (Odum and Kang, unpublished data) are examining more accurate data from summer, high light conditions.

\subsection{Improving model design}

Sunlight functions for the individual and Combined biome models represent average, long term intensities and do not include the random variations associated with actual conditions. Using observed sunlight intensities for individual and Combined Biome model simulations will help determine the relative contribution of each biome to community metabolism. 
The Mini model suggests respiration quotients are very important in determining even short term concentrations of carbon dioxide and oxygen (Engel, 1994). It is possible these quotients vary seasonally and between biomes, as plant species and communities develop. Recalibrating the individual and Combined Biome models with empirically determined respiration quotients will increase the predictive ability of these models.

Simulations identify absorption and/or release of carbon dioxide by calcareous materials (Fig. 25) as an important factor determining long term composition of the atmosphere inside Biosphere 2 under materially closed conditions. The simplified carbonate systems in these models may not be adequate to represent the interactions exhibited by the acid-base equilibria, especially in the terrestrial biome models. The absorption rate used to calibrate the individual biome models is also subject to sensor error and an incomplete data set during closure period. The isotope work by Severinghaus (1994) may be used in future simulations to more accurately quantify this process rate.

\subsection{Analogies with Biosphere 1}

Although not entirely planned, the metabolism in Biosphere 2 turned out to be a good analog for that of the whole planet earth. For example, the excess organic matter respired during closure caused carbon dioxide to increase and oxygen to decrease. Similarly, the burning of fossil fuels on earth is now producing excess carbon dioxide in the atmosphere. In both systems, the excess carbon dioxide is buffered by carbonates in the ocean, in soils, and/or concrete. The study of Biosphere 2 provides the important insight that long range oxygen levels on earth are partly controlled by the cycles of calcium and carbonate, and that only by considering the interaction of these biogeochemical cycles can we gain a realistic understanding of planet homeostasis and feedback mechanisms. Biosphere 2, because of its analogous properties to the earth, provides the opportunity to investigate the potential implications for the global carbon and oxygen budgets that may result from climate forcing and a changing atmosphere. The shorter turnover time and spatial dimensions of Biosphere 2 provide clear signals for ecosystem level indicators of community metabolism and interacting geochemical cycles and identify the key processes that form the linked system. Tracking the interactions between the oxygen, carbon, and calcium cycles in Biosphere 2 will provide insight for researchers studying these biogeochemical cycles on earth. The holistic perspective provided by Biosphere 2, so necessary to understand system level responses inside the enclosure, will help shape the emerging interdisciplinary approach to understanding earth.

\section{Acknowledgements}

The authors wish to express their appreciation to Dr Bruno Marino and Daeseok Kang for their assistance in the completion of this work. Part of this work was 
from a thesis for Master of Science in Environmental Engineering, University of Florida, Gainesville, 1994. Work was supported by a contract between Space Biosphere Ventures and the University of Florida. H.T. Odum Principal Investigator.

\section{References}

Adey, W.H., 1991. Dynamic Aquaria: Building Living Ecosystems. Academic Press, New York.

Bierner, M., 1994. Preliminary estimates of biomass production in wilderness biomes. Unpublished manuscript provided by Space Biosphere Ventures.

Beyers, R., Odum, H.T., 1994. Ecological Microcosms. Springer-Verlag, Berlin.

Dempster, W., 1993. Unpublished memo. Used with permission from Space Biosphere Ventures.

Engel, V.C., 1994. Simulation of carbon dioxide and oxygen inside Biosphere 2. Unpublished Master's Thesis. Department of Environmental Engineering, University of Florida, Gainesville, FL.

Odum, H.T., 1967. Biological circuits and the marine systems of Texas. In: Olson, T.A., Burgess, F.J. (Eds.), Pollution and Marine Ecology. Wiley-Interscience, New York, pp. 99-157.

Odum, H.T., 1971. Environment, Power, and Society. Wiley-Interscience, New York.

Odum, H.T., 1983. Systems Ecology. John Wiley and Sons, New York.

Severinghaus, J., 1994. Oxygen loss in Biosphere 2. EOS American Geophysical Union 75 (3), 33-37. 